\title{
Increased mortality, morbidities, and costs after heart transplantation in heterotaxy syndrome and other complex situs arrangements
}

Son Q. Duong, MD, ${ }^{\mathrm{a}}$ Justin Godown, MD, ${ }^{\mathrm{b}}$ Jonathan H. Soslow, MD, MSCI, ${ }^{\mathrm{b}}$ Cary Thurm, PhD, Matt Hall, PhD, ${ }^{\mathrm{c}}$ Sandeep Sainathan, MD, ${ }^{\mathrm{d}}$ Victor O. Morell, MD, ${ }^{\mathrm{d}}$ Debra A. Dodd, MD, ${ }^{\mathrm{b}}$ and Brian Feingold, MD, MS ${ }^{\mathrm{a}, \mathrm{e}}$

\section{ABSTRACT}

Objectives: Identify pediatric heart transplant (HT) recipients with heterotaxy and other complex arrangements of cardiac situs (heterotaxy/situs anomaly) and compare mortality, morbidities, length of stay (LOS), and costs to recipients with congenital heart disease without heterotaxy/situs anomaly.

Methods: Using linked registry data (2001-2016), we identified 186 HT recipients with heterotaxy/situs anomaly and 1254 with congenital heart disease without heterotaxy/situs anomaly. We compared post-HT outcomes in univariable and multivariable time-to-event analyses. LOS and cost from HT to discharge were compared using Wilcoxon rank-sum tests. Sensitivity analyses were performed using stricter heterotaxy/situs anomaly group inclusion criteria and through propensity matching.

Results: HT recipients with heterotaxy/situs anomaly were older (median age, 5.1 vs 1.6 years; $P<.001)$ and more often black, Asian, Hispanic, or "other" nonwhite $(54 \%$ vs $32 \% ; P<.001)$. Heterotaxy/situs anomaly was independently associated with increased mortality (hazard ratio, $1.58 ; 95 \%$ confidence interval, 1.19-2.09; $P=.002$ ), even among 6-month survivors (hazard ratio, $1.86 ; 95 \%$ confidence interval, 1.09-3.16; $P=.021)$. Heterotaxy/situs anomaly recipients more commonly required dialysis (odds ratio, 2.58 ; $95 \%$ confidence interval, $1.51-4.42 ; P=.001$ ) and cardiac reoperation (odds ratio, $1.91 ; 95 \%$ confidence interval, 1.17-3.11; $P=.010$ ) before discharge. They had longer ischemic times (19.2 additional minutes [range, $10.9-27.5$ minutes]; $P<.001$ ), post-HT intensive care unit LOS (16 vs 13 days; $P=.012$ ), and hospital LOS (26 vs 23 days; $P=.005)$. Post-HT hospitalization costs were also greater $(\$ 447,604$ vs $\$ 379,357 ; P=.001)$.

Conclusions: Heterotaxy and other complex arrangements of cardiac situs are associated with increased mortality, postoperative complications, LOS, and costs after HT. Although increased surgical complexity can account for many of these differences, inferior late survival is not well explained and deserves further study.

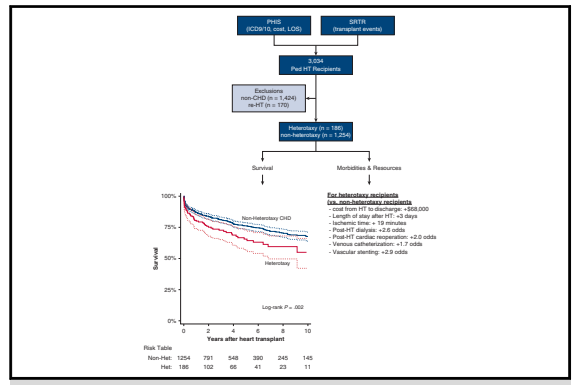

Increased mortality, morbidities, and costs for heart transplant recipients with heterotaxy.

\section{Central Message}

Heart transplantation in patients with heterotaxy/cardiac situs anomalies is associated with increased mortality, early morbidities, and higher care costs compared with transplantation for other congenital heart diseases.

\section{Perspective}

Children with heterotaxy who undergo heart transplantation are understudied. We found they have increased mortality, early morbidities (including need for dialysis, cardiac reoperation, and vascular intervention), and care costs relative to nonheterotaxy transplant recipients. Anticipation of these features may aid decision making around transplant candidacy and during postoperative care.

See Editorial Commentary page 741.
Departments of ${ }^{\mathrm{a}}$ Pediatrics, ${ }^{\mathrm{d}}$ Cardiothoracic Surgery, and ${ }^{\mathrm{e}}$ Clinical and Translational Science, University of Pittsburgh School of Medicine, Pittsburgh, Pa; ${ }^{b}$ Division of Pediatric Cardiology, Monroe Carell Jr. Children's Hospital at Vanderbilt, Nash-

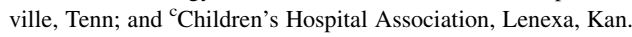

This work was supported in part by the Patrick J. Dick Memorial Fund for Cardiology Research at UPMC Children's Hospital of Pittsburgh (to S.D.) and the Katherine Dodd Faculty Scholar Program at Vanderbilt University (to J.G.). Research reported in this publication was supported by the National Heart, Lung, and Blood Institute of the National Institutes of Health (K23HL123938) (to J.S.).

The data reported here were supplied by the Minneapolis Medical Research Foundation as the contractor for the Scientific Registry of Transplant Recipients. The inter- pretation and reporting of these data are the responsibility of the author(s) and in no way should be seen as an official policy of or interpretation by the Scientific Registry of Transplant Recipients or the US government.

Received for publication June 11, 2018; revisions received Oct 22, 2018; accepted for publication Nov 4, 2018.

Address for reprints: Brian Feingold, MD, MS, Department of Pediatrics, University of Pittsburgh School of Medicine, 4401 Penn Ave, Faculty Pavilion Floor 5, Pittsburgh, PA 15224 (E-mail: Brian.Feingold@chp.edu). $0022-5223 / \$ 36.00$

Copyright (C) 2018 by The American Association for Thoracic Surgery https://doi.org/10.1016/j.jtcvs.2018.11.022 

Abbreviations and Acronyms
$\mathrm{CAV}=$ coronary allograft vasculopathy
CHD = congenital heart disease
DSXM $=$ donor-specific cross-match
$\mathrm{ECMO}=$ extracorporeal membrane oxygenation
eGFR = estimated glomerular filtration rate
HT = heart transplant
ICD = International Classification of Diseases
ICU = intensive care unit
LOS = length of stay
$\mathrm{OPO}=$ organ procurement organization
PHIS = Pediatric Health Information System
PTLD $=$ posttransplant lymphoproliferative disease
SRTR $=$ Scientific Registry of Transplant Recipients
$\mathrm{VAD}=$ ventricular assist device

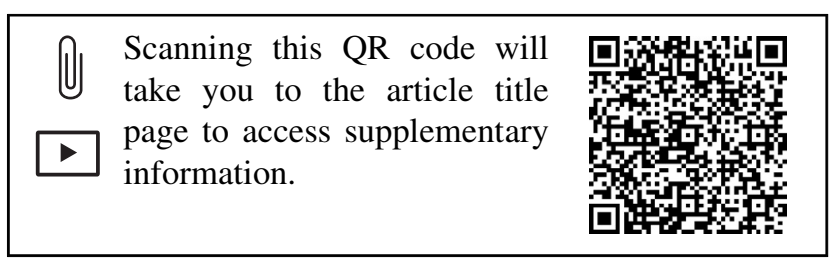

Heterotaxy is characterized by organ laterality defects and complex congenital heart disease (CHD). ${ }^{1}$ Survival has historically been poor compared with other forms of CHD, particularly early after cardiac surgery due to technical difficulties posed by anomalies of situs. ${ }^{2,3}$ Heart transplantation (HT) has been reported for patients with heterotaxy in case reports ${ }^{4}$ and single center series. ${ }^{5}$ However, due to the lack of an indicator variable in transplant registries, there has been no large, multicenter analysis of outcomes and complications for recipient with heterotaxy; thus, limited information is available to guide providers and patients.

We used a novel linkage between the Scientific Registry of Transplant Recipients (SRTR) and the Pediatric Health Information System (PHIS) databases to describe survival, length of stay (LOS), hospitalization costs, and morbidities following HT for children and young adults with heterotaxy and other complex arrangements of cardiac situs (ie, heterotaxy/sinus anomaly). We hypothesized that HT recipients with heterotaxy/situs anomaly would have increased early post-HT mortality and greater LOS and hospital costs from HT to discharge compared with recipients with $\mathrm{CHD}$ in the absence of heterotaxy/situs anomaly. Following the early post-HT phase, we hypothesized that survival for heterotaxy/situs anomaly recipients would be similar to nonheterotaxy/situs anomaly recipients. We did not specify hypothesis regarding morbidities given the multiple morbidities that were explored.

\section{METHODS \\ Database Linkage and Patient Selection}

Database linkage at the patient level used indirect identifiers and was performed and validated as previously described. ${ }^{6}$ SRTR includes data on all donors, wait-listed candidates, and recipients in the United States, submitted by the members of the Organ Procurement and Transplantation Network. The Health Resources and Services Administration of the US Department of Health and Human Services provides oversight to the activities of the Organ Procurement and Transplantation Network and SRTR contractors. ${ }^{7}$ PHIS is an administrative database of International Classification of Diseases ninth and 10th edition (ICD-9/10) codes, hospital charges, and resource use for hospital-based patient encounters across $>45$ US children's hospitals. ${ }^{8}$ We mapped ICD-10 to ICD-9 using the Agency for Healthcare Research and Quality MapIT Tool ${ }^{9}$ (Table E1).

The linked database contained 3062 records of transplant and follow-up data from November 2001 to November 2016. After exclusions for retransplantation $(\mathrm{n}=189)$ and missing/non-CHD diagnosis $(\mathrm{n}=1433)$, analysis was performed on patients who underwent primary HT for CHD $(n=1440$ [47\%]). Heterotaxy/situs anomaly $(n=186)$ was defined as any patient with an SRTR diagnosis of CHD plus $\geq 1$ of the following ICD-9/10 codes within their entire PHIS record: 759.3/Q89.3 (situs inversus); 759.0/ Q89.01, Q89.09 (polysplenia/asplenia); or 746.87/Q24.0 (dextrocardia). Primary HT recipients not meeting these criteria formed the comparison group of CHD recipients without heterotaxy/situs anomaly $(\mathrm{n}=1254)$.

\section{Data Sources and Collection}

From SRTR we collected recipient sex, race, diagnosis (CHD/nonCHD), history of sternotomy and/or thoracic surgery for CHD, and HT date; age, waitlist urgency status, patient location (intensive care unit [ICU]/in-hospital/outside hospital), and use of inotropic support, mechanical ventilation, ventricular assist device (VAD), and extracorporeal membrane oxygenation (ECMO) at HT; dialysis while listed; pre-HT serum creatinine; donor-specific cross-match (DSXM); ischemic time; and donor and recipient organ procurement organizations (OPOs). The following were collected from SRTR: treatment for infection or acute rejection, cardiac reoperation, and posttransplant dialysis during the HT admission; latest vital status (ie, alive/deceased/retransplanted) with date; cause of death; infection or rejection requiring rehospitalization; and occurrence of posttransplant lymphoproliferative disease (PTLD) and coronary allograft vasculopathy (CAV).

PHIS data were used to characterize the underlying CHD phenotypes in the study population; characterize surgeries, procedures, and infections that occurred after HT during the HT hospitalization; and quantify inpatient costs and the durations of post-HT mechanical ventilation, ICU LOS, and hospital LOS. All costs were adjusted for inflation to 2016 US dollars using the medical component of the consumer price index and were calculated from charges using hospital and year-specific cost-to-charge ratios.

To characterize the spectrum of underlying CHD phenotypes we identified the following cardiovascular morphology ICD-9/10 diagnosis codes applied during the transplant hospitalization in PHIS: ICD-9 codes beginning with 745 (Bulbus cordis anomalies and anomalies of cardiac septal closure), 746 (Other congenital anomalies of the heart), and 747 (Other congenital anomalies of the circulatory system), and ICD-10 codes Q20Q28 (Congenital malformations of the circulatory system). Similarly, cardiovascular surgeries and procedures that occurred after HT during the transplant hospitalization were assessed by identifying ICD-9 procedure codes that begin with $35,36,37,38$, and 39 (Operations on the cardiovascular system) and ICD-10 procedure codes beginning with 02 (Heart and great vessels). To explore differences in encapsulated bacterial infections, 
we identified the relevant ICD-9/10 diagnosis codes assigned during the transplant admission (Table E2). Duplicated codes were only counted once per subject.

\section{Statistical Analysis}

Data are described as median (interquartile range) or count (\%), as appropriate. Odds and hazard ratios are reported with $95 \%$ confidence intervals (CIs). Categorical data were compared using the $\chi^{2}$ or Fisher exact test, as appropriate. Continuous data were compared using the Wilcoxon rank-sum test. Post-HT procedures were compared between the groups by calculating the odds ratio (OR) of procedure with Fisher exact 95\% CI. Univariate survival was assessed with the Kaplan-Meier estimator and compared using the log-rank test. Survival curves were truncated when approximately $10 \%$ of patients were left at-risk. Because death competes with postdischarge infection, rejection, PTLD, and CAV, each of these outcomes was analyzed by competing-risks regression ${ }^{10}$ in which the competing risk of death/retransplantation was considered. Significant differences in outcomes between the groups in univariate comparison were adjusted for covariates using multivariable Cox proportional hazards, logistic, and linear regression models, as appropriate. To build the models the following covariates were tested for a univariate effect on outcome: race, age, year of HT, prior sternotomy and/or prior CHD surgery, dialysis on waitlist, DSXM result, waitlist urgency status, patient location, inotropic support, mechanical ventilation, VAD, and ECMO at HT. For analysis of post-HT renal failure requiring dialysis, we included pre-HT dialysis, glomerular filtration rate (eGFR) $<40 \mathrm{~mL} / \mathrm{min} / 1.73 \mathrm{~m}^{2}$, and ischemic time $>3.5$ hours. eGFR was estimated using the modified Schwartz formula, ${ }^{11}$ capped at $200 \mathrm{~mL} / \mathrm{min} / 1.73 \mathrm{~m}^{2}$. Procurement distance was estimated by computing the geodesic distance between donor and recipient OPO ZIP codes, ${ }^{12}$ and used as a covariate in linear regression analysis of ischemic time between the groups. Covariates with $P$ values $\leq .1$ in univariate comparisons were included in the multivariable model with the main variable of interest. Covariates with Wald test $P>.1$ in the full multivariable models were then dropped from the analysis to produce final models. The proportional hazards assumption was assessed for Cox models by visualization of log-log survival plots and with regression of the scaled Schoenfeld residuals on the identity function of time. ${ }^{13}$ Covariates that violated the proportional hazards assumption were stratified in Cox models. Presence of significant interaction terms were assessed with the likelihood-ratio test.

Missing data were compared across groups (Table E3). For pre-HT VAD and dialysis, missing data were rare $(<3 \%)$ and imputed as "no." For DSXM, prior sternotomy and/or prior CHD repair, and prior univentricular CHD repair, missing data were assumed to be randomly missing and imputed using multiple imputation. Subjects with missing outcomes data were excluded for analysis of that outcome.

\section{Sensitivity Analyses}

To address potential misclassification based on the nonspecificity of the dextrocardia and situs inversus ICD codes, subjects were reclassified using stricter inclusion criteria of only polysplenia/asplenia ICD codes and survival analysis was repeated. To address possible misspecification of model variables, we modified all Cox models to include additional user-selected, clinically relevant covariates. Finally, to address the potential for bias from inadequate/incomplete selection of model covariates, we performed propensity score matching in which the probability of a subject being classified into the heterotaxy/situs anomaly group was determined by logistic regression on characteristics listed in Table E4. Missing data were coded as a categorical dummy variable for each covariate, allowing patients with missing data to be matched. Matching was 1:2 using a matching caliper of one-fifth the standard deviation of the logit of the propensity scores. Covariate balance was assessed through calculation of the standardized mean bias, with values $>0.2$ considered significant.

All analyses were performed using Stata version 13 (StataCorp, College Station, Tex). This research was approved by the Vanderbilt University and

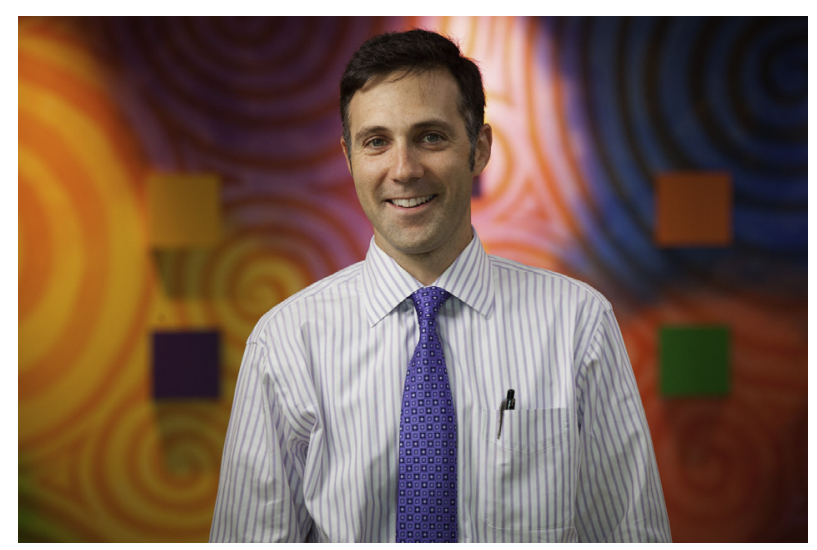

VIDEO 1. Senior author, Dr Brian Feingold, medical director, Heart Transplantation at UPMC Children's Hospital of Pittsburgh, explains the importance and relevance of the article. Video available at: https://www. jtcvs.org/article/S0022-5223(18)32970-2/fulltext.

University of Pittsburgh Institutional Review Boards, PHIS, and SRTR. See highlights of the study in Video 1.

\section{RESULTS \\ Group Characteristics}

Group characteristics at transplant are shown in Table 1. The heterotaxy/situs anomaly group was older (median age, 5.1 years vs 1.6 years; $P<.001$ ) and more often African American, Asian, Hispanic, or "other" nonwhite $(54 \%$ vs $32 \% ; P<.001)$. A lower proportion in the heterotaxy/situs anomaly group had reduced eGFR $(3 \%$ vs $9 \% ; P=.004)$. We found no other significant differences between groups, including proportion with prior sternotomy and/or surgery for CHD (76\% vs $68 \% ; P=.196)$. There were no significant differences in missing data between groups (Table E3).

ICD codes used to define the heterotaxy/situs anomaly group were distributed as follows: dextrocardia (71 out of 186 [38\%]); polysplenia/asplenia (31 out of 186 [17\%]); polysplenia/asplenia with dextrocardia (34 out of 186 [18\%]); polysplenia/asplenia with situs inversus (17 out of 186 [9\%]); polysplenia/asplenia, dextrocardia, and situs inversus (15 out of $186[8 \%]$ ); dextrocardia with situs inversus (12 out of $186[6 \%]$ ); and situs inversus alone (6 out of 186 [3\%]). Table E5 demonstrates the spectrum of underlying CHD phenotypes described by ICD codes. The heterotaxy/situs anomaly group was enriched for codes for endocardial cushion defect, common ventricle, pulmonary outflow tract obstruction, disorders of pulmonary and systemic venous return, truncus abnormalities, and conduction abnormalities. The nonheterotaxy/situs anomaly CHD group was enriched for hypoplastic left heart syndrome, coronary artery anomalies, and secundum atrial septal defects. See Table E5 for full data. 


\section{Survival After Transplant}

Median follow-up was 3.03 years (range, 1.006.91 years). The heterotaxy/situs anomaly group demonstrated inferior post-HT survival in unadjusted analysis $(P=.002)$ (Figure $1, A)$. Univariable and multivariable Cox model specifications are shown in Tables E6 and E7. After adjustment for African-American race, calendar year of HT, and pre-HT ECMO, heterotaxy/situs anomaly was associated with an increased mortality compared with nonheterotaxy/situs anomaly CHD (hazard ratio [HR], $1.58 ; 95 \%$ CI, 1.19-2.09; $P=.002$ ). These findings persisted amongst 6-month post-HT survivors in unadjusted $(P=.007)$ (Figure $1, B)$ and adjusted analyses (HR, 1.86; 95\% CI, 1.09-3.16; $P=.021$; adjusted for age and African-American race). There were no significant differences in cause of death between the groups (Table 2) or in the cumulative incidences of PTLD, CAV, admission for infection, or admission for rejection between the groups (Figure 2, $A-D$ ). Of note, 2 recipients $(1 \%)$ in the heterotaxy/situs anomaly group and $30(2 \%)$ in the nonheterotaxy/situs anomaly group underwent retransplantation during the observation period.

TABLE 1. Group characteristics at heart transplant

\begin{tabular}{|c|c|c|c|}
\hline Characteristic & $\begin{array}{c}\text { Nonheterotaxy CHD } \\
(\mathbf{n}=\mathbf{1 2 5 4})\end{array}$ & $\begin{array}{l}\text { Heterotaxy } \\
(\mathbf{n}=\mathbf{1 8 6})\end{array}$ & $P$ value* \\
\hline Age (y) & $1.6(0.3-9.0)$ & $5.1(0.8-11.5)$ & $<.001$ \\
\hline Female & $509(41)$ & $80(43)$ & .576 \\
\hline Weight $(\mathrm{kg}) \dagger$ & $9(4.1-22.0)$ & $15.2(6.4-30.0)$ & $<.001$ \\
\hline Height $(\mathrm{cm}) \dagger$ & $76(54-119)$ & $98(63-138)$ & $<.001$ \\
\hline Creatinine $(\mathrm{mg} / \mathrm{dL}) \dagger$ & $0.4(0.3-0.6)$ & $0.4(0.3-0.6)$ & .296 \\
\hline $\mathrm{eGFR}<40 \mathrm{~mL} / \mathrm{min} / 1.73 \mathrm{~m}^{2} \dagger$ & $111 / 1223(9)$ & $5 / 182(3)$ & .004 \\
\hline $\begin{array}{l}\text { Race } \\
\text { White } \\
\text { African American } \\
\text { Asian } \\
\text { Hispanic } \\
\text { Other }\end{array}$ & $\begin{array}{c}852(68) \\
166(13) \\
20(2) \\
188(15) \\
28(2)\end{array}$ & $\begin{array}{c}89(46) \\
36(19) \\
10(5) \\
42(23) \\
9(5)\end{array}$ & $<.001 \ddagger$ \\
\hline Year of transplant & $2011(2007-2014)$ & $2011(2008-2014)$ & .267 \\
\hline $\begin{array}{l}\text { Listing status } \\
\text { 1A } \\
1 \mathrm{~B} \\
2\end{array}$ & $\begin{array}{c}1023(82) \\
156(12) \\
75(6)\end{array}$ & $\begin{array}{c}146(78) \\
31(17) \\
9(5)\end{array}$ & $.261 \ddagger$ \\
\hline $\begin{array}{l}\text { Location } \\
\text { ICU } \\
\text { Hospitalized, non-ICU } \\
\text { Not hospitalized }\end{array}$ & $\begin{array}{l}637(51) \\
209(17) \\
408(33)\end{array}$ & $\begin{array}{l}85(46) \\
37(20) \\
64(34)\end{array}$ & $.357 \ddagger$ \\
\hline Inotrope support & $645(51)$ & $97(52)$ & .875 \\
\hline VAD support ${ }^{\dagger}$ & $86(7)$ & $13(8)$ & .878 \\
\hline Pre-HT dialysis $\dagger$ & $28(2)$ & $6(3)$ & .434 \\
\hline ECMO & $94(7)$ & $8(5)$ & .206 \\
\hline Mechanical ventilation & $276(22)$ & $36(20)$ & .769 \\
\hline Positive DSXM + & 203/1004 (20) & $22 / 149(15)$ & .207 \\
\hline Prior sternotomy and/or surgery for $\mathrm{CHD} \dagger$ & $512 / 826(62)$ & $94 / 137(69)$ & .152 \\
\hline If prior sternotomy and/or surgery for CHD, underwent univentricular repair $\dagger$ & $314 / 461(68)$ & $63 / 83(76)$ & .196 \\
\hline Distance between donor and recipient OPO (miles) & $494(200-638)$ & $328(103-579)$ & .047 \\
\hline Total ischemic time (min) & $230(191-273)$ & $240(198-289)$ & .020 \\
\hline
\end{tabular}




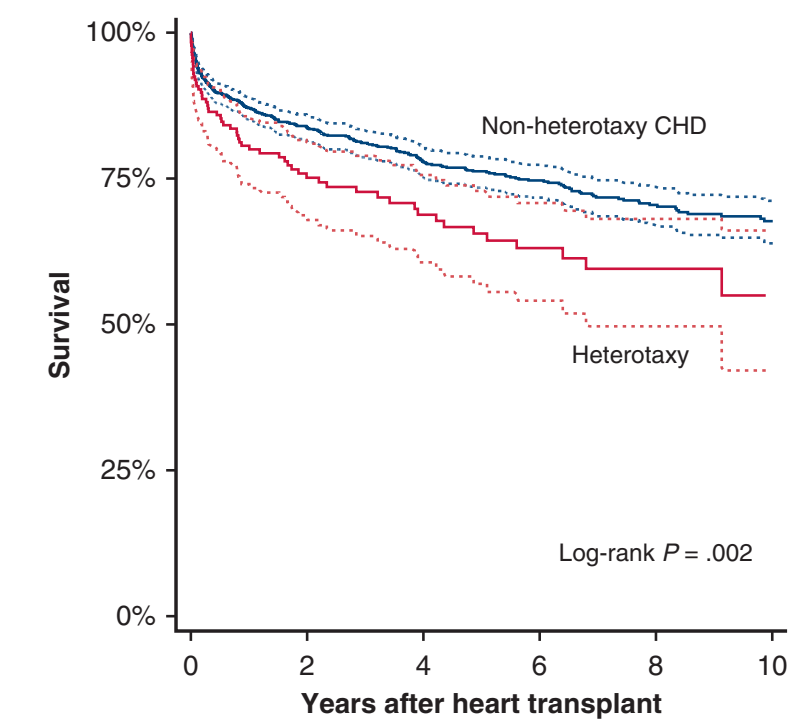

$\begin{array}{rcccccc}\text { Risk Table } & & & & & & \\ \text { Non-Het: } & 1254 & 791 & 548 & 390 & 245 & 145 \\ \text { Het: } & 186 & 102 & 66 & 41 & 23 & 11\end{array}$

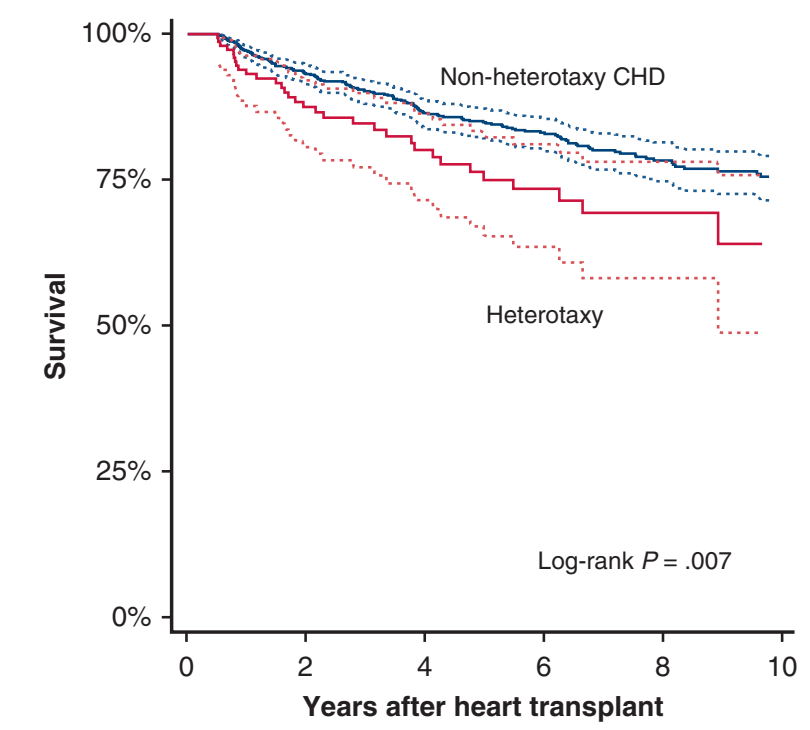

Risk Table

$\begin{array}{rcccccc}\text { Non-Het: } & 1061 & 791 & 548 & 390 & 245 & 145 \\ \text { Het: } & 152 & 102 & 66 & 41 & 23 & 11 \\ \text { B } & & & & & & \end{array}$

FIGURE 1. A, Survival after heart transplantation with heterotaxy/situs anomaly. Univariable Kaplan-Meier estimator showing that patients with heterotaxy/situs anomaly (Het) (red) have inferior survival after heart transplantation compared with other patients with congenital heart disease (CHD) in the absence of heterotaxy/situs anomalies (Non-Het) (blue). The curves sharply diverge early after transplant (approximately 6-12 mo) and continue to diverge more gradually thereafter, consistent with survival differences between the groups both early and later after transplantation. B, Survival after heart transplantation with Het, conditional upon survival to 6-months after transplantation. Univariable Kaplan-Meier estimator showing that among 6-month postheart transplant survivors, patients with Het (red) have decreased survival compared with patients with CHD in Non-Het (blue). This analysis confirms a survival difference between the groups occurring outside the perioperative phase.

\section{Posttransplant Complications, LOS, and Cost}

Perioperative complications analyzed from SRTR are shown in Table 3. Univariable and multivariable logistic model specifications are shown in Tables E8 and E9. Cardiac reoperation (adjusted OR, $1.91 ; P=.010$ ) and renal failure requiring dialysis (adjusted OR, 2.58; $P=.001$ ) were increased among heterotaxy/situs anomaly recipients

TABLE 2. Cause of death

\begin{tabular}{lccc}
\hline \multicolumn{1}{c}{ Cause } & $\begin{array}{c}\text { Nonheterotaxy } \\
\text { congenital heart } \\
\text { disease }(\mathbf{n}=\mathbf{2 9 1})\end{array}$ & $\begin{array}{c}\text { Heterotaxy } \\
(\mathbf{n}=\mathbf{5 9})\end{array}$ & $\boldsymbol{P}$ value* \\
\hline Cardiovascular & $70(24)$ & $12(20)$ & .615 \\
Cerebrovascular & $21(7)$ & $6(10)$ & 1 \\
\hline Graft failure & $83(29)$ & $16(27)$ & .875 \\
Hemorrhage & $12(4)$ & $3(5)$ & 1 \\
\hline Infection & $29(10)$ & $8(14)$ & .725 \\
Malignancy & $6(2)$ & $3(5)$ & .180 \\
\hline Pulmonary & $28(10)$ & $10(17)$ & .109 \\
Other & $48(16)$ & $8(14)$ & .698 \\
\hline Unknown & $26(9)$ & $4(7)$ & .592 \\
\hline Van
\end{tabular}

Values are presented as $\mathrm{n}(\%)$. *Fisher exact test of proportions. prior to discharge following HT. Heterotaxy/situs anomaly recipients were more commonly treated for infection before discharge following HT (adjusted OR, 1.54; $P=.015$ ); however, we found no difference in PHIS-recorded encapsulated bacterial infection ICD codes between the groups $(2.9 \%$ vs $2.3 \% ; P=.638)$. There were similar proportions with acute rejection during the HT hospitalization $(17 \%$ each; $P=.916$ ).

As shown in Table 4, data from PHIS support increased complications between HT and hospital discharge. ICD procedure codes for venous catheterization (OR, 1.65; $P=.010$ ), insertion of nondrug-eluting peripheral (noncoronary) vessel stent(s) $(\mathrm{OR}, 2.94 ; P=.016)$, and hemodialysis $(\mathrm{OR}, 2.67 ; P=.013)$ were more common among heterotaxy/situs anomaly recipients. We also found greater duration of mechanical ventilation after HT for heterotaxy/ situs anomaly recipients (median 5 vs 4 days; $P=.039$ ) (Table 5), with a greater proportion of heterotaxy/situs anomaly recipients requiring mechanical ventilation for $>1$ week after HT (44 vs 36\%; adjusted OR, 1.70; $95 \%$ CI, 1.20-2.40; $P=.003$ ) (Table 3).

Ischemic times were longer for the heterotaxy/situs anomaly group (median, 240 minutes [interquartile range, 198-289 minutes] vs 230 minutes [interquartile 

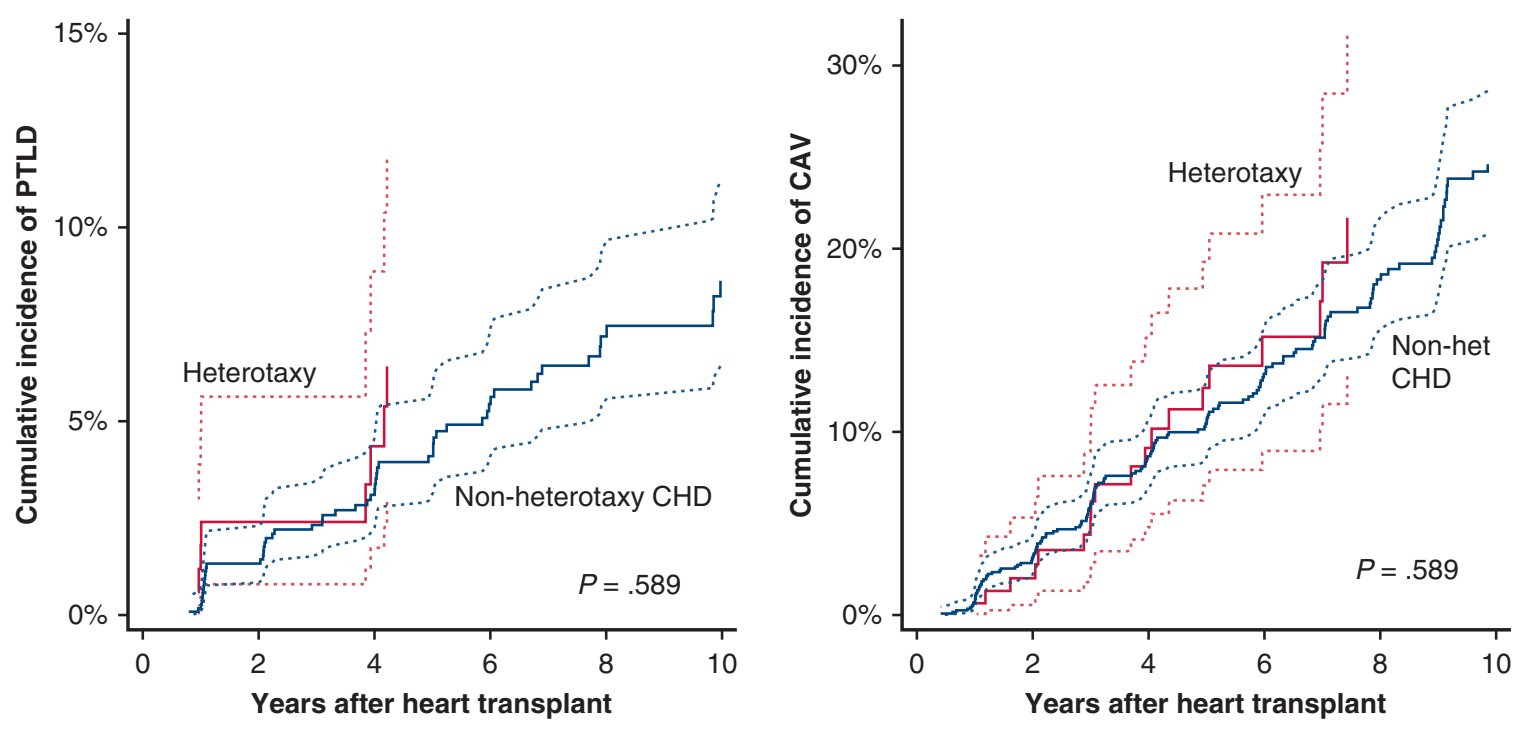

A

B
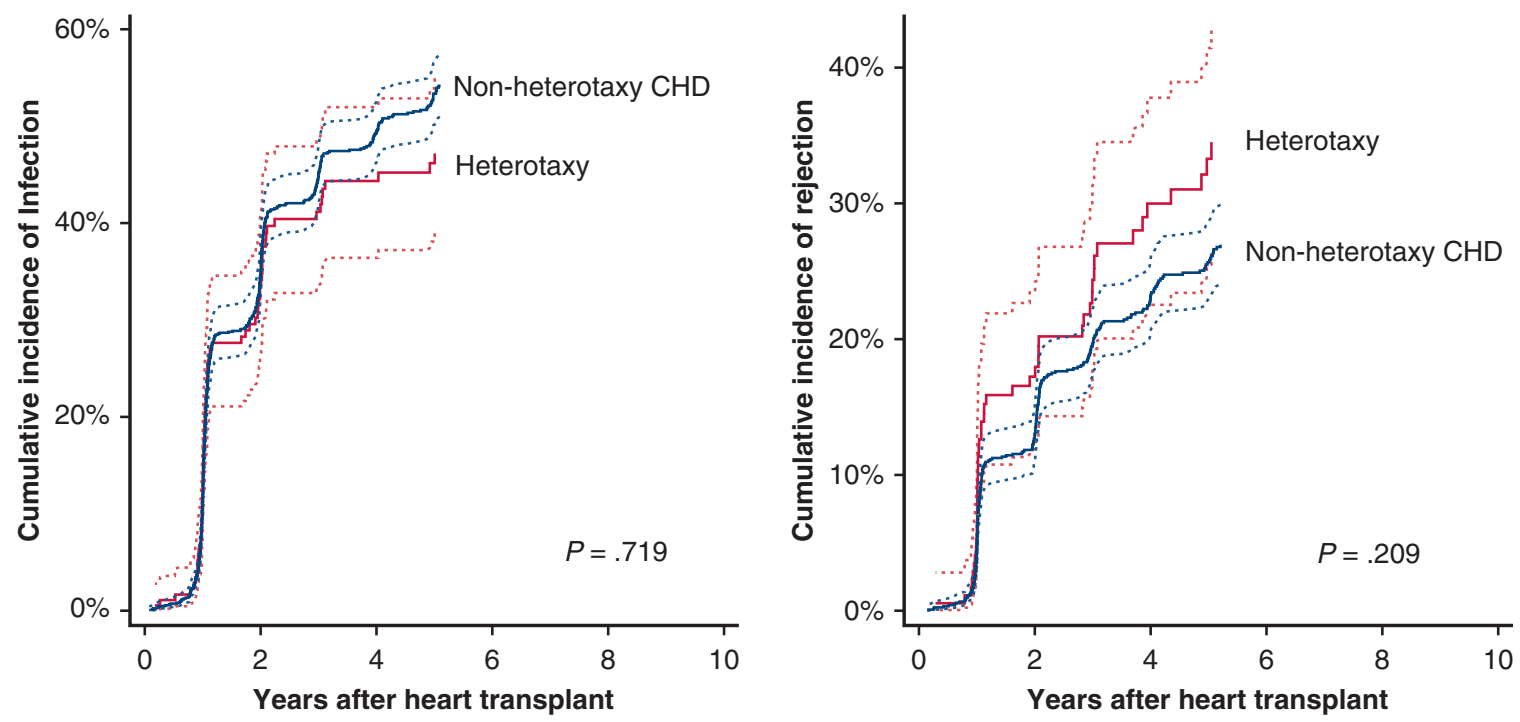

C

D

\begin{tabular}{|c|c|c|c|c|c|c|c|c|c|c|c|c|c|}
\hline & Year & 2 & 4 & 6 & 8 & 10 & & Year & 2 & 4 & 6 & 8 & 10 \\
\hline$\frac{\pi}{0} \div$ & Rejection & 139 & 227 & 252 & 252 & 252 & త্ & Rejection & 28 & 43 & 47 & 47 & 47 \\
\hline \begin{tabular}{|ll}
0 & $\| 1$ \\
0 & $=$
\end{tabular} & PTLD & 14 & 29 & 44 & 52 & 56 & $\frac{0}{2}$ & PTLD & 4 & 6 & 8 & 8 & 8 \\
\hline 홍우 & CAV & 33 & 79 & 107 & 130 & 148 & $\stackrel{\oplus}{I} \subseteq$ & CAV & 3 & 11 & 16 & 19 & 19 \\
\hline Z I & Infection & 377 & 504 & 537 & 537 & 537 & & Infection & 55 & 70 & 73 & 73 & 73 \\
\hline
\end{tabular}

\section{E}

FIGURE 2. Cumulative incidences of development of common postheart transplant comorbidities. A, Posttransplant lymphoproliferative disease ( $P T L D$ ). B, Coronary artery vasculopathy $(C A V)$. C, First hospitalization for infection. D, First hospitalization for rejection. In each panel, patients with heterotaxy/ situs anomaly ( $r e d)$ are compared with patients with congenital heart disease $(C H D)$ in the absence of heterotaxy/situs anomalies (blue). All cumulative incidences depicted account for the competing outcome of death/retransplantation. E, Cumulative number of events at each time point are shown in the table below. There were no statistically significant differences observed for these outcomes. Dotted lines depict $95 \%$ confidence intervals and the numbers at risk in each group are shown at bottom of the panel. 
TABLE 3. Perioperative outcomes

\begin{tabular}{|c|c|c|c|c|c|c|}
\hline Outcome & $\begin{array}{c}\text { Nonheterotaxy } \\
\text { congenital heart } \\
\text { disease }\end{array}$ & Heterotaxy & $\begin{array}{c}\text { Unadjusted } \\
\text { odds ratio } \\
(\mathbf{9 5} \% \text { CI })\end{array}$ & $\begin{array}{c}\text { Unadjusted } \\
P \text { value }\end{array}$ & $\begin{array}{c}\text { Adjusted } \\
\text { odds ratio } \\
(95 \% \text { CI })\end{array}$ & $\begin{array}{c}\text { Adjusted } \\
P \text { value }\end{array}$ \\
\hline Infection during HT admission & $294 / 974(30)$ & $57 / 145(49)$ & $1.50(1.04-2.15)$ & .030 & $1.54(1.06-2.25)^{*}$ & $.015^{*}$ \\
\hline Cardiac reoperation & 97/979 (10) & $27 / 143(19)$ & $2.12(1.32-3.38)$ & .002 & $1.91(1.17-3.11) \dagger$ & $.010^{\dagger}$ \\
\hline Post-HT renal failure requiring dialysis & $77 / 1253(6)$ & $23 / 186(12)$ & $2.16(1.32-3.53)$ & .002 & $2.58(1.51-4.42) \ddagger$ & $.001 \ddagger$ \\
\hline Mechanically ventilated $>1 \mathrm{wk}$ & $429 / 1202(36)$ & $78 / 177(44)$ & $1.42(1.3-1.95)$ & .032 & $1.70(1.20-2.40) \S$ & $.003 \S$ \\
\hline Rejection during HT admission & $187 / 1124(17)$ & $29 / 137(17)$ & $1.02(0.67-1.57)$ & .916 & - & - \\
\hline
\end{tabular}

Values are presented as $\mathrm{n}(\%) . C I$, Confidence interval; $H T$, heart transplant. *Infection during HT admission adjusted for: year, pre-HT extracorporeal membrane oxygenation, pre-HT mechanical ventilation, home location at HT, positive donor-specific cross-match, and history of prior univentricular CHD repair. †Adjusted for patient race, ventricular assist device, and mechanical ventilation pre-HT. ¥Adjusted for pre-HT dialysis, estimated glomerular filtration rate $<40 \mathrm{~mL} / \mathrm{min} / 1.73 \mathrm{~m}^{2}$, ischemic time $>3.5$ hours, extracorporeal membrane oxygenation, ICU location at HT, and female race. §Adjusted for mechanical ventilation pre-HT, pre-HT extracorporeal membrane oxygenation, and age. Source data: Scientific Registry of Transplant Recipients.

range, 191-273 minutes]; $P=.020$ ), despite a shorter median distance between donor and recipient OPOs (328 miles [interquartile range, 103-579 miles] vs 494 miles [200-638 miles]; $P=.047$ ). After adjustment for significant covariates (distance, Hispanic race, outpatient location at HT, and history of prior univentricular CHD repair), heterotaxy/situs anomaly was associated with $19.2(95 \% \mathrm{CI}, 10.4-27.6 ; P<.001)$ additional minutes of ischemia. Table E10 shows model specifications.

As shown in Table 5, recipients with heterotaxy/situs anomaly had longer median post-HT ICU (16 days [interquartile range, $0-190$ days] vs 13 days [interquartile range, $0-458$ days]; $P=.012$ ) and total hospital LOS (26 days [interquartile range, 16-49 days] vs 23 days [interquartile range, 14-42 days]; $P=.005$ ), conditional on survival to discharge. Post-HT hospitalization costs were also greater for heterotaxy/situs anomaly recipients: median $\$ 447,604$ vs $\$ 379,357 ; P=.001$ amongst all recipients; $\$ 421,040$ versus $\$ 360,211 ; P=.001$ amongst those surviving to discharge. Across most subcategories, costs were significantly greater for heterotaxy/situs anomaly recipients (Tables E11 and E12).

\section{Sensitivity Analyses}

After forcing clinically important variables of age and history of prior univentricular repair into the primary outcome Cox model, we still observed increased mortality among heterotaxy/situs anomaly recipients (HR, 1.52; 95\% CI, 1.13-2.03; $P=.005$; adjusted for AfricanAmerican race, year of HT, pre-HT ECMO, age, and history of prior univentricular repair). After reclassification of patients with heterotaxy based solely on ICD codes for polysplenia/asplenia, heterotaxy/situs anomaly remained an independent predictor of mortality (HR, $1.51 ; 95 \% \mathrm{CI}$, 1.04-2.21; $P=.032$ ) adjusted for African-American race, year of HT, and ECMO at HT (Figure E1). In propensity score-matched cohorts, 186 recipients with heterotaxy/situs anomaly were matched to 368 non-heterotaxy/situs anomaly CHD HT recipients (Table E4 and Figure E2). Heterotaxy/situs anomaly was associated with increased mortality (HR, $1.53 ; 95 \% \mathrm{CI}, 1.09-2.16 ; P=.015)$.

TABLE 4. International Classification of Diseases ninth edition (ICD-9) procedure codes after heart transplant

\begin{tabular}{|c|c|c|c|c|c|}
\hline ICD-9 description & ICD-9 code* & $\begin{array}{l}\text { Heterotaxy } \\
(\mathbf{n}=177)\end{array}$ & $\begin{array}{c}\text { Nonheterotaxy } \\
\text { congenital heart } \\
\text { disease }(n=1199)\end{array}$ & $\begin{array}{c}\text { Odds ratio } \\
\text { (95\% confidence } \\
\text { interval }) \dagger\end{array}$ & $P$ value $\dagger$ \\
\hline Other revision of vascular procedure & 39.49 & $4(2.3)$ & $9(0.8)$ & $3.06(0.99-9.47)$ & .074 \\
\hline $\begin{array}{l}\text { Insertion of nondrug-eluting peripheral } \\
\text { (noncoronary) vessel stent(s) }\end{array}$ & 39.9 & $8(4.5)$ & $19(1.6)$ & $2.94(1.29-6.68)$ & .016 \\
\hline Hemodialysis & 39.95 & $11(6.2)$ & $29(2.4)$ & $2.67(1.33-5.39)$ & .013 \\
\hline Venous cutdown & 38.94 & $5(2.8)$ & $14(1.2)$ & $2.46(0.91-6.66)$ & .086 \\
\hline Venous catheterization for renal dialysis & 38.95 & $8(4.5)$ & $23(1.9)$ & $2.42(1.09-5.39)$ & .050 \\
\hline Angioplasty of other noncoronary vessel(s) & 39.5 & $18(10.2)$ & $79(6.6)$ & $1.60(0.94-2.74)$ & .085 \\
\hline Venous catheterization, not elsewhere classified & 38.93 & $47(26.6)$ & $215(17.9)$ & $1.65(1.15-2.38)$ & .010 \\
\hline No posttransplant procedure performed & None & $44(24.9)$ & $378(31.5)$ & $0.72(0.50-1.03)$ & .081 \\
\hline
\end{tabular}

Values for heterotaxy and nonheterotaxy congenital heart disease are presented as n (\%). ICD-9, International Classification of Diseases ninth edition. *ICD-10 procedure codes were translated to ICD-9. †Fisher exact test. Source data: Pediatric Health Information System database. 
TABLE 5. Resource use and length of stay (LOS) after heart transplant (HT)

\begin{tabular}{|c|c|c|c|}
\hline Outcome & Nonheterotaxy congenital heart disease & Heterotaxy & $P$ value* \\
\hline Ventilation days & $4(1-14)$ & $5(2-21)$ & .039 \\
\hline iNO days & $2(0-5)$ & $2(0-5)$ & .176 \\
\hline ECMO post-HT & $172 / 1030(14)$ & $22 / 177(12)$ & .564 \\
\hline ICU LOS after $\mathrm{HT}(\mathrm{d}) \dagger$ & $13(0-458)$ & $16(0-190)$ & .012 \\
\hline Hospital LOS after HT (d) $\dagger$ & $23(14-42)$ & $26(16-49)$ & .005 \\
\hline Cost after HT (2016 \$, thousands) & $\$ 379(\$ 262-\$ 580)$ & $\$ 448(\$ 320-\$ 709)$ & .001 \\
\hline Cost after HT, if survived to discharge (2016 \$, thousands) $\dagger$ & $\$ 360(\$ 252-\$ 527)$ & $\$ 421(\$ 299-\$ 666)$ & .001 \\
\hline
\end{tabular}

Values are presented as n (\%) or median (interquartile range). $i N O$, Inhaled nitric oxide; $E C M O$, extra-corporeal membrane oxygenation; ICU, intensive care unit; $L O S$, length of stay; $H T$, heart transplant. *Binary data compared with Fisher exact test, continuous data with Wilcoxon rank-sum test. †Conditional upon survival to discharge. Source data: Pediatric Health Information System database.

\section{DISCUSSION}

\section{Significance of Main Findings}

We provide the most extensive report of post-HT outcomes for children with heterotaxy/situs anomaly from a large sample of US pediatric HT centers (Figure 3). To date, knowledge about HT outcomes for heterotaxy patients has been limited to anecdotal experience, case reports, and single center series. Jacobs and colleagues ${ }^{14}$ reported suboptimal outcomes in 5 HT recipients with heterotaxy, whereas Cohen and colleagues ${ }^{15}$ reported survival to 32 and 33 months for $2 \mathrm{HT}$ recipients with heterotaxy. In the largest previous report, 29 pediatric HT recipients with heterotaxy at a single-center showed no difference in survival relative to controls with dilated cardiomyopathy. ${ }^{5}$ Our main findings are that patients with heterotaxy/situs anomaly have decreased survival after HT and accrue greater costs for care with longer LOS after HT relative to other recipients who underwent HT for CHD (Figure 3). We also observed increased early post-HT morbidities, including longer ischemic times, increased prevalences of cardiac reoperation, catheterization, peripheral vessel stenting, and renal failure among heterotaxy/situs anomaly recipients. Although associations do not imply causality, these increased morbidities could explain greater mortality and resource use among heterotaxy/situs anomaly recipients.

Not well explained is the late survival difference we observed. Although the heterotaxy/situs anomaly group was older and disproportionately non-white, both known risk factors for inferior survival after pediatric $\mathrm{HT}^{16}$ the late survival difference persisted after controlling for these. Potentially, greater medical/surgical complexity or accrued pre-HT comorbidities for heterotaxy/situs anomaly recipients persist after HT and influences late survival but was not captured in our analysis. Though we found no significant differences in prior sternotomies between the groups, these data do not convey number, timing, or complexity of cardiac surgeries prior to HT. Similarly, although we found no difference in time-to-event for common causes of late post-HT mortality (ie, rejection, infection, PTLD, and CAV), we lack details about severity of these events.
Rejection associated with hemodynamic compromise imparts significantly higher risk of death than rejection without hemodynamic compromise. ${ }^{17,18}$ Likewise, PTLD and CAV severity influence survival. ${ }^{19,20}$ The broad, multisystem involvement of heterotaxy syndrome, ${ }^{21}$ including the potential for overwhelming bacterial sepsis with asplenia/functional asplenia, may also contribute to the observed survival difference. In a recently reported neonatal heterotaxy syndrome cohort, extracardiac causes were implicated in $18 \%$ of deaths. ${ }^{22}$

\section{Perioperative Morbidities}

The primary strength of our analysis is the ability to identify and analyze patients with heterotaxy and other complex arrangements of cardiac situs in a large, multicenter cohort, thereby providing novel insights into post-HT survival, perioperative complications, procedures, and resource utilization. We hypothesized that HT recipients with heterotaxy/situs anomaly have worse perioperative outcomes due to increased surgical complexity related to anomalies of cardiac position and venous return. ${ }^{4,23-26}$ Indeed, we have found evidence of this. Despite shorter procurement distances, adjusted ischemic time was 19 minutes more in the heterotaxy/ situs anomaly group, suggesting greater surgical complexity and longer cardiopulmonary bypass durations. Increases in ischemic and bypass times in heterotaxy have been reported by others, ${ }^{5}$ and both are risk factors for mortality in children undergoing cardiac surgery. ${ }^{14,27}$ Also consistent with our hypothesized increased surgical complexity, we found that patients with heterotaxy/situs anomaly who were transplant recipients underwent cardiac reoperation about twice as frequently as nonheterotaxy/situs anomaly CHD recipients, and more commonly underwent cardiac catheterization and peripheral vascular stent placement before discharge from the HT hospitalization. Unfortunately, we do not know the indications for reoperations, catheterizations, or vascular stent placements to further characterize these events. 


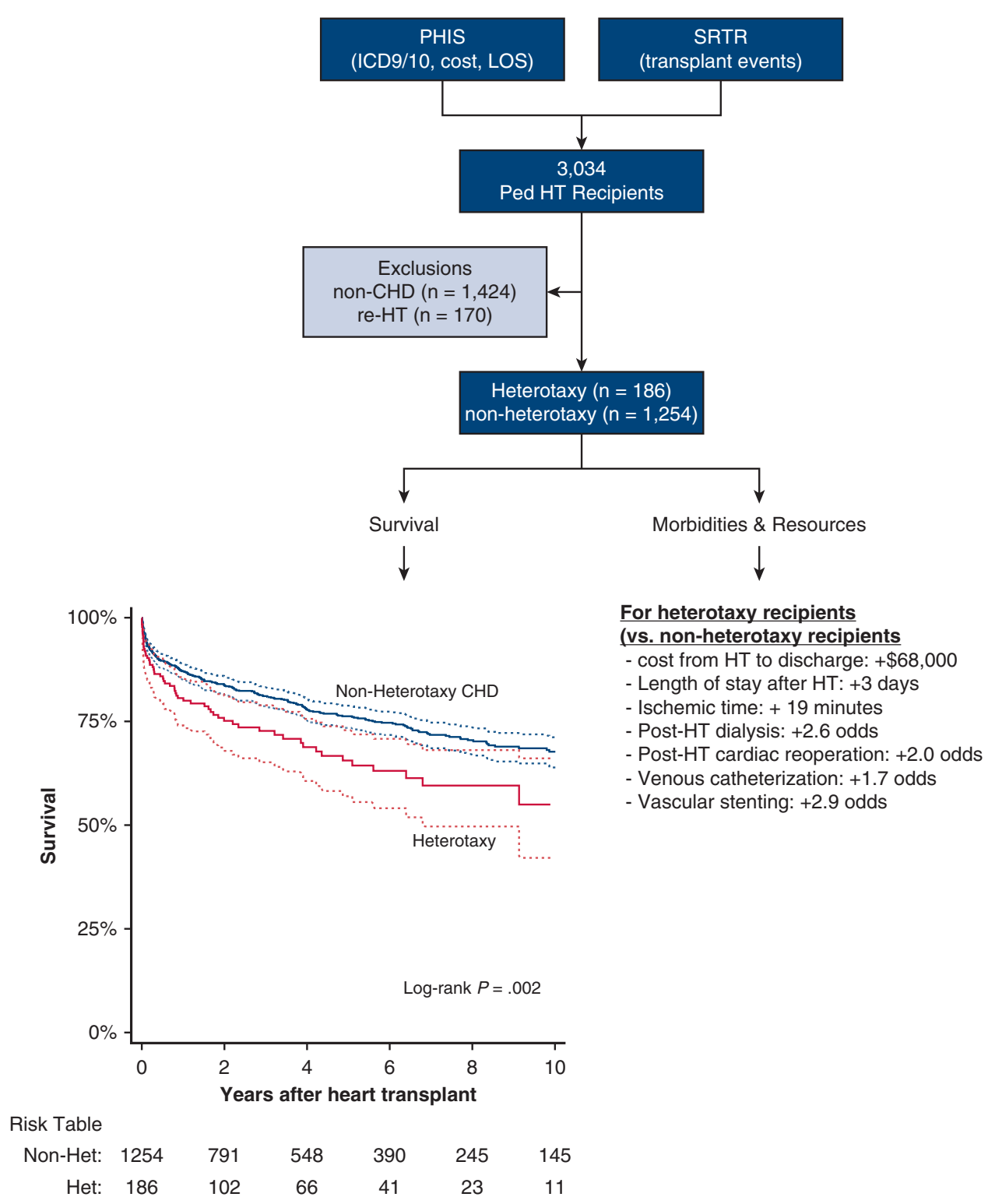

FIGURE 3. We leveraged 2 large, independent databases (Pediatric Health Information Systems $[P H I S]$ and the Scientific Registry of Transplant Recipients $[S R T R])$ to identify pediatric heart transplant $(H T)$ recipients with heterotaxy and other complex situs arrangements (a previously unstudied cohort across multiple centers), and compare posttransplant outcomes to patients with congenital heart disease $(C H D)$ in the absence of heterotaxy. Dotted lines depict $95 \%$ confidence intervals and the numbers at risk in each group are shown beneath the graph. LOS, Length of stay.

Infection, renal failure requiring dialysis, and longer duration of mechanical ventilation were also more common postoperatively in heterotaxy/situs anomaly recipients. However, the occurrence of 1 may contribute to the need for another (eg, renal failure leading to volume overload contributing to prolonged mechanical ventilation.) Unfortunately, we cannot disentangle these associations in our dataset. Although asplenia predisposes to bacteremia/sepsis, ${ }^{28}$ we found no differences in the presence of ICD-coded encapsulated bacterial infections between the groups. This may be due to relatively short observation, analysis of both asplenic and polysplenic patients in the heterotaxy/ situs anomaly group (which cannot be unbundled with ICD-9 coding), inability to identify causative organisms, or insufficient coding. Heterotaxy has been associated with prolonged mechanical ventilation and tracheostomy after cardiac surgery, ${ }^{29}$ which has been attributed to increased prevalence of ciliary dyskinesia. ${ }^{30}$ Although ciliary dyskinesia has been implicated in polycystic kidney disease, ${ }^{31}$ and heterotaxy syndrome is associated with genitourinary anomalies, we found no reports of predisposition toward renal failure in heterotaxy. Given that longer bypass times are independently associated with kidney injury in adults undergoing $\mathrm{HT}^{32}$ and children undergoing surgery 
for $\mathrm{CHD},{ }^{32-34}$ a relationship between these in heterotaxy/ situs anomaly recipients is feasible.

\section{LOS and Costs}

It is not surprising that post-HT LOS and costs were greater for heterotaxy/situs anomaly recipients given the increased complications observed. These increases are similar to what has been reported for pediatric HT recipients with other complicating features, such as requirement for mechanical circulatory support ${ }^{35}$ or allosensitization, ${ }^{36}$ and in whom HT is commonly performed. Therefore, on the basis of increased LOS and costs alone, children with heterotaxy/situs anomaly should not be excluded from transplant consideration.

\section{Limitations}

Our analysis has many limitations. Our definition of heterotaxy/situs anomaly relied on ICD codes, which can be ambiguous. Errors and incomplete coding may also exist. ICD codes do not allow us to distinguish between leftand right-isomerism, making our population clinically heterogeneous. Furthermore, heterotaxy can be difficult to categorize, even with access to more detailed anatomic information than was available. ${ }^{37}$ However, the racial distribution of our heterotaxy/situs anomaly cohort mirrors other reports of increased prevalence in AfricanAmerican, Asian, and Hispanic individuals. ${ }^{38-41}$ Furthermore, our heterotaxy/situs anomaly cohort is enriched for diagnoses common in heterotaxy (eg, anomalous pulmonary and systemic venous return, pulmonary outflow anomalies, and congenital heart block). These observations support the validity of our cohort. Still, it is likely that some nonheterotaxy recipients in our primary analysis were misclassified, particularly those who met criteria based on having the ICD-9 diagnosis codes of dextrocardia and/or situs inversus without polysplenia. These codes may have been applied when the heart alone was malpositioned or in patients with situs inversus totalis. However, this would only diminish the differences between the groups. Also, when we included only patients with ICD codes for asplenia/polysplenia in sensitivity analysis, the survival difference remained.

Other potential limitations are our model selection techniques and validity of the control group. Although we utilized data-driven model selection to identify relevant covariates for the regression models, some potentially important variables (eg, age and prior univentricular repair) did not meet inclusion criteria. However, when we locked these clinically relevant covariates into the multivariable model, we still observed increased mortality of heterotaxy/situs anomaly recipients. Further, when we controlled for possible selection bias through propensity score matching, the survival difference remained. These sensitivity analyses suggest that our conclusions are robust, adding strength to our findings.

Because our sample is limited only to HT recipients at PHIS-member hospitals, primarily children and young adults, our findings should not be generalized to adults. Also, because PHIS does not capture outpatient encounters or track patients across hospitals, our analysis of postdischarge complications is limited to those reported at yearly intervals in the SRTR. The Pediatric Heart Transplant Study $^{42}$ dataset collects greater detail on some of these events and thus may be a good choice for linkage to PHIS to further explore associations of postdischarge infection, rejection, PTLD, and CAV on late survival in heterotaxy syndrome. Ideally, a dataset that contains a more granular focus on heterotaxy could verify our findings, particularly some of the less-expected findings, such as prolonged mechanical ventilation or renal failure.

\section{CONCLUSIONS}

In a population-based analysis of administrative data on pediatric HT recipients with heterotaxy and other complex arrangements of cardiac situs we observed increased mortality, longer LOS, and greater costs of care from HT surgery to discharge relative to other nonheterotaxy/situs anomaly HT recipients with CHD (Figure 3). Early mortality and resource use differences could be explained by increased early postoperative complications, including more frequent cardiac reoperations and vascular stenting; however, the reason(s) for the difference in late survival is unclear. Further study is warranted.

\section{Conflict of Interest Statement}

Dr Brian Feingold participates in clinical trials funded by Novartis and receives research funding from Abbott Diagnostics. All other authors have nothing to disclose with regard to commercial support.

\section{References}

1. Loomba RS, Ahmed MM, Spicer DE, Backer CL, Anderson RH. Manifestations of bodily isomerism. Cardiovasc Pathol. 2016;25:173-80.

2. Landis BJ, Cooper DS, Hinton RB. CHD associated with syndromic diagnoses: peri-operative risk factors and early outcomes. Cardiol Young. 2016;26:30-52.

3. Jonas RA. Surgical management of the neonate with heterotaxy and long-term outcomes of heterotaxy. World J Pediatr Congenit Heart Surg. 2011;2:264-74.

4. Deuse T, Reitz BA. Heart transplantation in situs inversus totalis. J Thorac Cardiovasc Surg. 2010;139:501-3.

5. Larsen RL, Eguchi JH, Mulla NF, Johnston JK, Kitts J, Kuhn MA, et al. Usefulness of cardiac transplantation in children with visceral heterotaxy (asplenic and polysplenic syndromes and single right-sided spleen with levocardia) and comparison of results with cardiac transplantation in children with dilated cardiomyopathy. Am J Cardiol. 2002;89:1275-9.

6. Godown J, Thurm C, Dodd DA, Soslow JH, Feingold B, Smith AH, et al. A unique linkage of administrative and clinical registry databases to expand analytic possibilities in pediatric heart transplantation research. Am Heart J. 2017; 194:9-15.

7. Scientific Registry of Transplant Recipients. The SRTR database: Overview. Available at: https://www.srtr.org/about-the-data/the-srtr-database/. Accessed December 1, 2017. 
8. Pediatric Health Information System. Overview. Available at: https://www. childrenshospitals.org/programs-and-services/data-analytics-and-research/pediatricanalytic-solutions/pediatric-health-information-system. Accessed December 1, 2017.

9. MapIT Automated In-house Stand-alone Mapping Tool. Posted March 2014. Rockville, MD: Agency for Healthcare Research and Quality. Available at: https://www.qualityindicators.ahrq.gov/resources/toolkits.aspx.

10. Pepe MS, Mori M. Kaplan-Meier, marginal or conditional probability curves in summarizing competing risks failure time data? Stat Med. 1993;12:737-51.

11. Schwartz GJ, Munoz A, Schneider MF, Mark RH, Kaskel F, Warady BA, et al. New equations to estimate GFR in children with CKD. J Am Soc Nephrol. 2009;20:629-37.

12. Nichols A. VINCENTY: Stata module to calculate distances on the Earth's surface. Statistical Software Components. 2017; S456815.

13. Grambsch PM, Therneau TM. Proportional hazards tests and diagnostics based on weighted residuals. Biometrika. 1994;81:515-26.

14. Jacobs JP, Asante-Korang A, O'Brien SM, Chai PJ, Dadlani GH, RodriquezFazzi GL, et al. Lessons learned from 119 consecutive cardiac transplants for pediatric and congenital heart disease. Ann Thorac Surg. 2011;91:1248-54.

15. Cohen MS, Schultz AH, Tian ZY, Donaghue DD, Weinberg PM, Gaynor JW, et al. Heterotaxy syndrome with functional single ventricle: does prenatal diagnosis improve survival? Ann Thorac Surg. 2006;82:1629-36.

16. Rossano JW, Cherikh WS, Chambers DC, Goldfarb S, Khush K, Kucheryavaya AY, et al. The Registry of the International Society for Heart and Lung Transplantation: twentieth pediatric heart transplantation report2017; focus theme: allograft ischemic time. J Heart Lung Transplant. 2017;36: 1060-9.

17. Everitt MD, Pahl E, Schectman KB, Zheng J, Ringewald JM, L'ecuyer T, et al. Rejection with hemodynamic compromise in the current era of pediatric heart transplantation: a multi-institutional study. J Heart Lung Transplant. 2011;30: 282-8.

18. Pahl E, Naftel DC, Canter CE, Frazier EA, Krklin JK, Morrow WR, et al. Death after rejection with severe hemodynamic compromise in pediatric heart transplant recipients: a multi-institutional study. J Heart Lung Transplant. 2001;20: 279-87.

19. Kindel SJ, Law YM, Chin C, Burch M, Kirklin JK, Naftel DC, et al. Improved detection of cardiac allograft vasculopathy: a multi-institutional analysis of functional parameters in pediatric heart transplant recipients. J Am Coll Cardiol. 2015;66:547-57.

20. Webber SA, Naftel DC, Fricker FJ, Olesnevich P, Blume ED, Addonizio L, et al. Lymphoproliferative disorders after paediatric heart transplantation: a multiinstitutional study. Lancet. 2006;367:233-9.

21. Kothari SS. Non-cardiac issues in patients with heterotaxy syndrome. Ann Pediatr Cardiol. 2014; 7:187-92.

22. Gottschalk I, Stressig R, Ritgen J, Herberg U, Breuer J, Vorndamme A, et al. Extracardiac anomalies in prenatally diagnosed heterotaxy syndrome. Ultrasound Obstet Gynecol. 2016;47:443-9.

23. Chang YL, Wei J, Chang CY, Chuang YC, Sue SH. Cardiac transplantation in situs inversus: two cases reports. Transplant Proc. 2008;40:2848-51.

24. Beiras-Fernandez A, Daebritz SH, Kaczmarek I, Kozlik-Feldman R, Tiete AR, Reichart B. Challenging venous reconstruction and heart transplantation in a patient with viscero-atrial situs inversus and complex congenital heart disease with Fontan circulation. J Heart Lung Transplant. 2007;26:290-2.

25. Rubay JE, d'Udekem Y, Sluysmans T, Ponlot R, Jacquet L, de Leval MR. Orthotopic heart transplantation in situs inversus. Ann Thorac Surg. 1995;60:460-2.
26. Michler RE, Sandhu AA. Novel approach for orthotopic heart transplantation in visceroatrial situs inversus. Ann Thorac Surg. 1995;60:194-7.

27. Ford MA, Almond CS, Gavreau K, Piercey G, Blume ED, Smoot LB, et al. Association of graft ischemic time with survival after heart transplant among children in the United States. J Heart Lung Transplant. 2011;30: 1244-9.

28. Prendiville TW, Bartol LL, Thompson WR, Fink DL, Holmes KW. Heterotaxy syndrome: defining contemporary disease trends. Pediatr Cardiol. 2010;31: 1052-8.

29. Swisher M, Jonas R, Tian X, Lee ES, Lo CW, Leatherbury L. Increased postoperative and respiratory complications in patients with congenital heart disease associated with heterotaxy. J Thorac Cardiovasc Surg. 2011;141:637-44.

30. Nakhleh N, Francis R, Giese RA, Tian X, Li Y, Zariwala MA, et al. High prevalence of respiratory ciliary dysfunction in congenital heart disease patients with heterotaxy. Circulation. 2012;125:2232-42.

31. Kathem SH, Mohieldin AM, Nauli SM. The roles of primary cilia in polycystic kidney disease. AIMS Mol Sci. 2014;1:27-46.

32. Boyle JM, Moualla S, Arrigain S, Worley S, Bakri MH, Starling RC, et al. Risks and outcomes of acute kidney injury requiring dialysis after cardiac transplantation. Am J Kidney Dis. 2006;48:787-96.

33. Pedersen KR, Povlsen JV, Christensen S, Pedersen J, Hjortholm K, Larsen SH, et al. Risk factors for acute renal failure requiring dialysis after surgery for congenital heart disease in children. Acta Anaesthesiol Scand. 2007;51:1344-9.

34. Chan KL, Ip P, Chiu CS, Cheung YF. Peritoneal dialysis after surgery for congenital heart disease in infants and young children. Ann Thorac Surg. 2003;76: 1443-9.

35. Godown J, Thurm C, Hall M, Dodd DA, Soslow JH, Mettler BA, et al. Mechanical circulatory support costs in children bridged to heart transplantation - analysis of a linked database. Am Heart J. 2018;201:77-85.

36. West SC, Webber SA, Zeevi A, Miller SA, Morell VO, Feingold B. Charges and resource utilization for pediatric heart transplantation across a positive virtual and/or cytotoxicity crossmatch. Pediatr Transplant. 2018;22.

37. Yim D, Nagata H, Lam CZ, Grosse-Wortmann L, Seed M, Jaeggi E, et al. Disharmonious patterns of heterotaxy and isomerism: how often are the classic patterns breached? Circ Cardiovasc Imaging. 2018;11:e006917.

38. Gatrad AR, Read AP, Watson GH. Consanguinity and complex cardiac anomalies with situs ambiguus. Arch Dis Child. 1984;59:242-5.

39. Kim SJ. Heterotaxy syndrome. Korean Circ J. 2011;41:227-32.

40. Kim SJ, Kim WH, Lim HG, Lee JY. Outcome of 200 patients after an extracardiac Fontan procedure. J Thorac Cardiovasc Surg. 2008;136:108-16.

41. Lin AE, Krikov S, Riehle-Colarusso T, Frias JL, Belmont J, Anderka M, et al. Laterality defects in the national birth defects prevention study (1998-2007): birth prevalence and descriptive epidemiology. Am J Med Genet A. 2014; 164A:2581-91.

42. Dipchand AI, Kirk R, Mahle WT, Tresler MA, Naftel DC, Pahl E, et al. Ten yr of pediatric heart transplantation: a report from the Pediatric Heart Transplant Study. Pediatr Transplant. 2013;17:99-111.

Key Words: heterotaxy, heart transplantation, congenital abnormalities, dextrocardia, situs inversus, registries, reoperation 


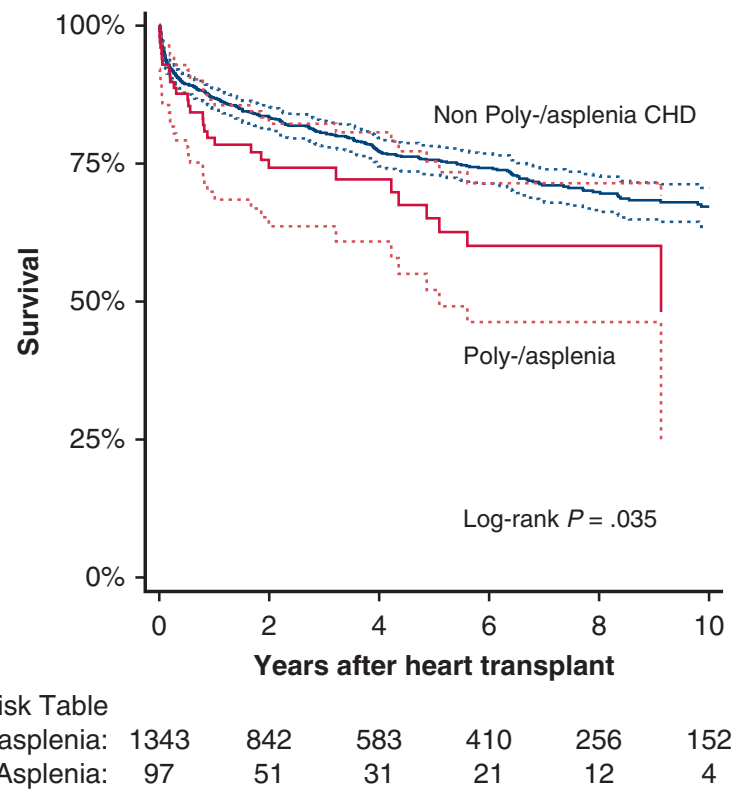

FIGURE E1. Sensitivity analysis of survival after heart transplant for patients meeting stricter inclusion criteria for heterotaxy. Univariable KaplanMeier analysis of survival after heart transplantation, using stricter inclusion criteria, defined as International Classification of Diseases code for polysplenia/asplenia only, to delineate heterotaxy recipients (red, poly-/asplenia) shows decreased survival compared with patients with congenital heart disease (CHD) in the absence of heterotaxy (blue, nonpoly-/aolysplenia CHD). This analysis shows a survival difference after transplant between the groups using this stricter definition of heterotaxy. Dotted lines depict $95 \%$ confidence intervals and the numbers at risk in each group are shown beneath the graph.

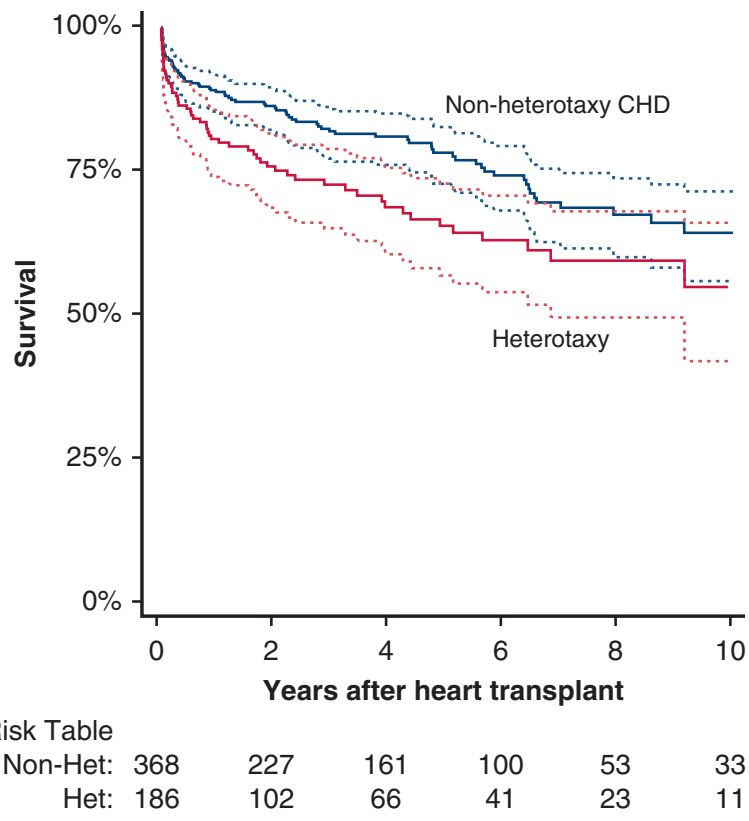

FIGURE E2. Sensitivity analysis of survival for patients with heterotaxy/ situs anomaly compared with a propensity score-matched group of nonheterotaxy/situs anomaly patients with congenital heart disease (CHD). Univariable Kaplan-Meier estimator showing that patients with heterotaxy/ situs anomaly (red) have inferior survival after heart transplantation compared with a propensity score-matched group of patients with CHD in the absence of heterotaxy (blue). There is a survival difference after transplant between the propensity score-matched groups. Propensity score matching was performed to address the potential for bias from inadequate/ incomplete selection of regression model covariates in our primary survival analysis (Figure 1). Dotted lines depict $95 \%$ confidence intervals and the numbers at risk in each group are shown beneath the graph. 
TABLE E1. International Classification of Disease 10th edition (ICD-10) mappings to International Classification of Diseases ninth edition (ICD-9) codes

\begin{tabular}{|c|c|c|c|}
\hline ICD-10 code* & ICD-10 description & ICD-9 code & ICD-9 description \\
\hline Q20.0 & Common arterial trunk & 745.0 & Common truncus \\
\hline Q20.1 & Double outlet right ventricle & 745.11 & Double outlet right ventricle \\
\hline Q20.3 & Discordant ventriculoarterial connection & 745.10 & Complete transposition of great vessels \\
\hline Q20.4 & Double inlet ventricle & 745.3 & Common ventricle \\
\hline Q20.5 & Discordant atrioventricular connection & 745.12 & Corrected transposition of great vessels \\
\hline Q21.0 & Ventricular septal defect & 745.4 & Ventricular septal defect \\
\hline Q21.1 & Atrial septal defect & 745.5 & Ostium secundum type atrial septal defect \\
\hline Q21.2 & Atrioventricular septal defect & 745.60 & Endocardial cushion defect, unspecified type \\
\hline Q22.0 & Pulmonary valve atresia & 746.01 & Atresia of pulmonary valve, congenital \\
\hline Q22.1 & Congenital pulmonary valve stenosis & 746.02 & Stenosis of pulmonary valve, congenital \\
\hline Q22.3 & Other congenital malformations of pulmonary valve & 746.00 & Congenital pulmonary valve anomaly, unspecified \\
\hline Q22.4 & Congenital tricuspid stenosis & 746.1 & Tricuspid atresia and stenosis, congenital \\
\hline Q22.5 & Ebstein's anomaly & 746.2 & Ebstein's anomaly \\
\hline Q22.6 & Hypoplastic right heart syndrome & 746.1 & Tricuspid atresia and stenosis, congenital \\
\hline Q22.8 & Other congenital malformations of tricuspid valve & 746.1 & Tricuspid atresia and stenosis, congenital \\
\hline Q23.0 & Congenital stenosis of aortic valve & 746.3 & Congenital stenosis of aortic valve \\
\hline Q23.1 & Congenital insufficiency of aortic valve & 746.4 & Congenital insufficiency of aortic valve \\
\hline Q23.2 & Congenital mitral stenosis & 746.5 & Congenital mitral stenosis \\
\hline Q23.3 & Congenital mitral insufficiency & 746.6 & Congenital mitral insufficiency \\
\hline Q23.4 & Hypoplastic left heart syndrome & 746.7 & Hypoplastic left heart syndrome \\
\hline Q24.0 & Dextrocardia & 746.87 & Malposition of heart and cardiac apex \\
\hline Q24.2 & Cor triatriatum & 746.82 & Cor triatriatum \\
\hline Q24.3 & Pulmonary infundibular stenosis & 746.83 & Infundibular pulmonic stenosis \\
\hline Q24.4 & Congenital subaortic stenosis & 746.81 & Subaortic stenosis \\
\hline Q24.5 & Malformation of coronary vessels & 746.85 & Coronary artery anomaly \\
\hline Q24.6 & Congenital heart block & 746.86 & Congenital heart block \\
\hline Q24.8 & Other specified congenital malformations of heart & 746.89 & Other specified congenital anomalies of heart \\
\hline Q24.9 & Congenital malformation of heart, unspecified & 746.9 & Unspecified congenital anomaly of heart \\
\hline Q25.0 & Patent ductus arteriosus & 747.0 & Patent ductus arteriosus \\
\hline Q25.1 & Coarctation of aorta & 747.10 & Coarctation of aorta (preductal) (postductal) \\
\hline Q25.2 & Atresia of aorta & 747.22 & Atresia and stenosis of aorta \\
\hline Q25.4 & Other congenital malformations of aorta & 747.20 & Anomaly of aorta, unspecified \\
\hline Q25.5 & Atresia of pulmonary artery & 747.31 & Pulmonary artery coarctation and atresia \\
\hline Q25.6 & Stenosis of pulmonary artery & 747.39 & $\begin{array}{l}\text { Other anomalies of pulmonary artery and pulmonary } \\
\text { circulation }\end{array}$ \\
\hline Q25.71 & Coarctation of pulmonary artery & 747.31 & Pulmonary artery coarctation and atresia \\
\hline Q25.72 & Congenital pulmonary arteriovenous malformation & 747.32 & Pulmonary arteriovenous malformation \\
\hline Q25.79 & Other congenital malformations of pulmonary artery & 747.39 & $\begin{array}{l}\text { Other anomalies of pulmonary artery and pulmonary } \\
\text { circulation }\end{array}$ \\
\hline Q25.8 & Other congenital malformations of other great arteries & 747.29 & Other anomalies of aorta \\
\hline Q26.1 & Persistent left superior vena cava & 747.49 & Other anomalies of great veins \\
\hline Q26.2 & Total anomalous pulmonary venous connection & 747.41 & Total anomalous pulmonary venous connection \\
\hline Q26.3 & Partial anomalous pulmonary venous connection & 747.42 & Partial anomalous pulmonary venous connection \\
\hline Q26.4 & Anomalous pulmonary venous connection, unspecified & 747.42 & Partial anomalous pulmonary venous connection \\
\hline
\end{tabular}


TABLE E1. Continued

\begin{tabular}{llcl}
\hline ICD-10 code* & \multicolumn{1}{c}{ ICD-10 description } & ICD-9 code & ICD-9 description \\
\hline Q26.8 & Other congenital malformations of great veins & 747.49 & Other anomalies of great veins \\
\hline Q27.0 & Congenital absence and hypoplasia of umbilical artery & 747.5 & Absence or hypoplasia of umbilical artery \\
\hline Q27.39 & Arteriovenous malformation, other site & 747.69 & $\begin{array}{c}\text { Anomalies of other specified sites of peripheral vascular } \\
\text { system }\end{array}$ \\
\hline Q27.8 & $\begin{array}{l}\text { Other specified congenital malformations of peripheral } \\
\text { vascular system }\end{array}$ & 747.69 & $\begin{array}{c}\text { Anomalies of other specified sites of peripheral vascular } \\
\text { system }\end{array}$ \\
\hline Q20.8 & $\begin{array}{c}\text { Other congenital malformations of cardiac chambers and } \\
\text { connections }\end{array}$ & 745.8 & $\begin{array}{c}\text { Other bulbus cordis anomalies and anomalies of cardiac } \\
\text { septal closure }\end{array}$ \\
\hline Q27.9 & $\begin{array}{c}\text { Anomaly of the peripheral vascular system, unspecified site } \\
\text { Congenital malformation of peripheral vascular system, } \\
\text { unspecified }\end{array}$ \\
\hline
\end{tabular}

*ICD-10 codes were mapped to the in-row ICD-9 codes for analysis. 
TABLE E2. List of International Classification of Disease (ICD) codes related to encapsulated bacterial infection

\begin{tabular}{|c|c|}
\hline $\begin{array}{l}\text { ICD } 9 \\
\text { or } 10 \text { code }\end{array}$ & Description \\
\hline 036.0 & Meningococcal meningitis \\
\hline 036.1 & Meningococcal encephalitis \\
\hline 036.2 & Meningococcemia \\
\hline 036.3 & Waterhouse-Friderichsen syndrome, meningococcal \\
\hline 036.40 & Meningococcal carditis, unspecified \\
\hline 036.41 & Meningococcal pericarditis \\
\hline 036.42 & Meningococcal endocarditis \\
\hline 036.43 & Meningococcal myocarditis \\
\hline 036.81 & Meningococcal optic neuritis \\
\hline 036.82 & Meningococcal arthropathy \\
\hline 036.89 & Other specified meningococcal infections \\
\hline 036.9 & Meningococcal infection, unspecified \\
\hline 038.2 & $\begin{array}{l}\text { Pneumococcal septicemia (Streptococcus } \\
\text { pneumoniae septicemia) }\end{array}$ \\
\hline 038.41 & Septicemia due to Hemophilus influenzae \\
\hline 041.2 & $\begin{array}{l}\text { Pneumococcus infection in conditions classified } \\
\text { elsewhere and of unspecified site }\end{array}$ \\
\hline 041.5 & $\begin{array}{l}H \text { influenzae infection in conditions classified } \\
\text { elsewhere and of unspecified site }\end{array}$ \\
\hline 320.1 & Pneumococcal meningitis \\
\hline 481. & $\begin{array}{l}\text { Pneumococcal pneumonia (S pneumoniae } \\
\text { pneumonia) }\end{array}$ \\
\hline 482.2 & Pneumonia due to $H$ influenzae \\
\hline 567.1 & Pneumococcal peritonitis \\
\hline A39.0 & Meningococcal meningitis \\
\hline A39.81 & Meningococcal encephalitis \\
\hline A39.2 & Acute meningococcemia \\
\hline A39.3 & Chronic meningococcemia \\
\hline A39.4 & Meningococcemia, unspecified \\
\hline A39.1 & Waterhouse-Friderichsen syndrome \\
\hline A 39.50 & Meningococcal carditis, unspecified \\
\hline A 39.53 & Meningococcal pericarditis \\
\hline A 39.51 & Meningococcal endocarditis \\
\hline A39.52 & Meningococcal myocarditis \\
\hline A39.82 & Meningococcal retrobulbar neuritis \\
\hline A39.83 & Meningococcal arthritis \\
\hline A39.84 & Postmeningococcal arthritis \\
\hline A39.89 & Other meningococcal infections \\
\hline A39.9 & Meningococcal infection, unspecified \\
\hline A40.3 & Sepsis due to $S$ pneumoniae \\
\hline A 40.3 & Sepsis due to $S$ pneumoniae \\
\hline A41.3 & Sepsis due to $H$ influenzae \\
\hline A41.3 & Sepsis due to $H$ influenzae \\
\hline
\end{tabular}

TABLE E2. Continued

\begin{tabular}{|c|c|}
\hline $\begin{array}{c}\text { ICD } 9 \\
\text { or } 10 \text { code }\end{array}$ & Description \\
\hline B95.3 & $\begin{array}{l}S \text { pneumoniae as the cause of diseases classified } \\
\text { elsewhere }\end{array}$ \\
\hline M00.111 & Pneumococcal arthritis, right shoulder \\
\hline M00.112 & Pneumococcal arthritis, left shoulder \\
\hline M00.119 & Pneumococcal arthritis, unspecified shoulder \\
\hline M00.121 & Pneumococcal arthritis, right elbow \\
\hline M00.122 & Pneumococcal arthritis, left elbow \\
\hline M00.129 & Pneumococcal arthritis, unspecified elbow \\
\hline M00.131 & Pneumococcal arthritis, right wrist \\
\hline M00.132 & Pneumococcal arthritis, left wrist \\
\hline M00.139 & Pneumococcal arthritis, unspecified wrist \\
\hline M00.141 & Pneumococcal arthritis, right hand \\
\hline M00.142 & Pneumococcal arthritis, left hand \\
\hline M00.149 & Pneumococcal arthritis, unspecified hand \\
\hline M00.151 & Pneumococcal arthritis, right hip \\
\hline M00.152 & Pneumococcal arthritis, left hip \\
\hline M00.159 & Pneumococcal arthritis, unspecified hip \\
\hline M00.161 & Pneumococcal arthritis, right knee \\
\hline M00.162 & Pneumococcal arthritis, left knee \\
\hline M00.169 & Pneumococcal arthritis, unspecified knee \\
\hline M00.171 & Pneumococcal arthritis, right ankle and foot \\
\hline M00.172 & Pneumococcal arthritis, left ankle and foot \\
\hline M00.179 & Pneumococcal arthritis, unspecified ankle and foot \\
\hline M00.18 & Pneumococcal arthritis, vertebrae \\
\hline M00.19 & Pneumococcal polyarthritis \\
\hline A 49.2 & $H$ influenzae infection, unspecified site \\
\hline B96.3 & $\begin{array}{l}\text { H influenzae as the cause of diseases classified } \\
\text { elsewhere }\end{array}$ \\
\hline J20.1 & Acute bronchitis due to $H$ influenzae \\
\hline G00.1 & Pneumococcal meningitis \\
\hline $\mathrm{J} 13$. & Pneumonia due to $S$ pneumoniae \\
\hline J14. & Pneumonia due to $H$ influenzae \\
\hline
\end{tabular}


TABLE E3. Comparison of proportions of missing characteristics and outcome data between primary study groups

\begin{tabular}{|c|c|c|c|}
\hline & $\begin{array}{c}\text { Nonheterotaxy } \\
\text { CHD }(n=1254)\end{array}$ & $\begin{array}{c}\text { Heterotaxy/situs } \\
\text { anomaly }(n=186)\end{array}$ & $P$ value* \\
\hline \multicolumn{4}{|l|}{ Missing pre-HT characteristics } \\
\hline Weight* & $1(0.1)$ & $1(1)$ & .242 \\
\hline Height* & $23(2)$ & $3(2)$ & 1 \\
\hline Creatinine* & $8(1)$ & $2(1)$ & .377 \\
\hline eGFR* & $31(2)$ & $4(2)$ & 1 \\
\hline VAD support & $52(4)$ & $5(3)$ & .424 \\
\hline Pre-HT dialysis* & $4(0.3)$ & $0(0)$ & 1 \\
\hline Positive DSXM & $250(20)$ & $37(20)$ & 1 \\
\hline Prior sternotomy and/or surgery for CHD & $428(34)$ & $49(26)$ & .037 \\
\hline $\begin{array}{l}\text { If prior sternotomy and/or surgery for CHD, underwent } \\
\text { univentricular repair* }\end{array}$ & $51 / 512(10)$ & $114(11)$ & .581 \\
\hline Heart- and great vessel-related ICD codes $\dagger$ & $55(4)$ & $9(5)$ & .706 \\
\hline \multicolumn{4}{|l|}{ Missing outcomes } \\
\hline Infection during HT admission & $280(22)$ & $41(22)$ & 1 \\
\hline Cardiac reoperation & $275(22)$ & $43(23)$ & .705 \\
\hline Post-HT dialysis* & $1(0.1)$ & $0(0)$ & 1 \\
\hline Rejection during $\mathrm{HT}$ admission & $130(10)$ & $15(8)$ & .364 \\
\hline Mechanical ventilation post-HT & $52(4)$ & $9(5)$ & .695 \\
\hline Post-HT ICD procedure codes & $52(4)$ & $9(5)$ & .695 \\
\hline Post HT iNO days & $52(4)$ & $9(5)$ & .695 \\
\hline Post-HT ECMO & $52(4)$ & $9(5)$ & 695 \\
\hline Hospital LOS after HT & $52(4)$ & $9(5)$ & .695 \\
\hline Cost after HT & $52(4)$ & $9(5)$ & .695 \\
\hline
\end{tabular}


TABLE E4. Propensity score-matched group characteristics at heart transplant (HT)

\begin{tabular}{|c|c|c|c|c|}
\hline & $\begin{array}{l}\text { Nonheterotaxy CHD } \\
\qquad(\mathbf{n}=\mathbf{3 6 8})\end{array}$ & $\begin{array}{l}\text { Heterotaxy/situs anomaly } \\
\qquad(\mathbf{n}=\mathbf{1 8 6})\end{array}$ & $\begin{array}{c}\text { Standardized } \\
\text { mean bias }\end{array}$ & $\boldsymbol{P}$ value $\dagger$ \\
\hline Age $(y)$ & & & & .656 \\
\hline $0-2$ & $132(36)$ & $62(33)$ & -0.053 & \\
\hline $2-12$ & $159(43)$ & $88(47)$ & 0.083 & \\
\hline$>12$ & $77(21)$ & $36(19)$ & -0.039 & \\
\hline Female & $143(38)$ & $80(43)$ & 0.085 & .347 \\
\hline Race & & & & $.943 \ddagger$ \\
\hline White & $180(49)$ & $89(48)$ & -0.021 & \\
\hline African American & $67(18)$ & $36(19)$ & 0.029 & \\
\hline Other & $121(33)$ & $61(33)$ & -0.002 & \\
\hline Year of transplant & $2011(2008-2014)$ & 2010 (2008-2014) & -0.033 & .665 \\
\hline Listing status & & & & $.758 \ddagger$ \\
\hline $1 \mathrm{~A}$ & $293(80)$ & $146(78)$ & -0.028 & \\
\hline 1B & $62(17)$ & $31(17)$ & -0.005 & \\
\hline 2 & $13(4)$ & $9(5)$ & 0.065 & \\
\hline Location & & & & $.849 \ddagger$ \\
\hline ICU & $176(48)$ & $85(46)$ & -0.043 & \\
\hline Hospitalized, non-ICU & $74(20)$ & $37(20)$ & -0.005 & \\
\hline Not hospitalized & $118(32)$ & $64(34)$ & 0.050 & \\
\hline Inotrope support & $201(55)$ & $97(52)$ & -0.050 & .582 \\
\hline VAD support & $29(8)$ & $13(7)$ & -0.034 & .708 \\
\hline Mechanical ventilation & $84(23)$ & $39(21)$ & -0.045 & .619 \\
\hline ECMO & $20(5)$ & $10(5)$ & -0.003 & .977 \\
\hline Positive DSXM* & $44(12)$ & $22(12)$ & -0.004 & $.997 \ddagger$ \\
\hline Missing DSXM & $74(20)$ & $37(20)$ & -0.005 & \\
\hline Prior sternotomy/CHD repair* & $177(48)$ & $94(51)$ & 0.049 & $.707 \ddagger$ \\
\hline Missing prior sternotomy/CHD repair & $94(26)$ & $49(26)$ & 0.018 & \\
\hline Prior univentricular repair surgery* & $117(32)$ & $63(34)$ & 0.044 & $.552 \ddagger$ \\
\hline Missing univentricular repair & $109(25)$ & $60(32)$ & 0.057 & \\
\hline
\end{tabular}

Data are presented as $\mathrm{n}(\%)$ or median (interquartile range). $C H D$, Congenital heart disease; $I C U$, intensive care unit; $V A D$, ventricular assist device; $E C M O$, extracorporeal membrane oxygenation; DXSM, donor-specific cross-match. *Missing data present. $\dagger$ Continuous data compared with rank-sum test, binary outcomes compared using $\chi^{2}$ test of proportions. ‡̦Tested across all groups. 
TABLE E5. Heart- and great vessel-related International Classification of Diseases (ICD) codes

\begin{tabular}{|c|c|c|c|c|c|}
\hline ICD-9 code* & ICD description & $\begin{array}{c}\text { Nonheterotaxy } \\
\text { CHD }(n=1199) \dagger\end{array}$ & $\begin{array}{c}\text { Heterotaxy/situs } \\
\text { anomaly }(\mathbf{n}=\mathbf{1 7 7}) \dagger\end{array}$ & $\begin{array}{c}\text { Absolute risk } \\
\text { difference }\end{array}$ & $\boldsymbol{P}$ value $\ddagger$ \\
\hline 745.69 & Other endocardial cushion defects & $60(5)$ & $61(34)$ & 0.295 & $<.001$ \\
\hline 745.3 & Common ventricle & $108(9)$ & $57(32)$ & 0.232 & $<.001$ \\
\hline 745.11 & Double outlet right ventricle & $101(8)$ & $48(27)$ & 0.187 & $<.001$ \\
\hline 747.41 & Total anomalous pulmonary venous return & $8(1)$ & $30(17)$ & 0.163 & $<.001$ \\
\hline 747.49 & Other anomalies of the great veins & $29(2)$ & $27(15)$ & 0.128 & $<.001$ \\
\hline 746.89 & Other specified congenital anomalies of heart & 209 (17) & $46(26)$ & 0.086 & .006 \\
\hline 745.10 & Complete transposition of great vessels & $61(5)$ & $23(13)$ & 0.079 & $<.001$ \\
\hline 74.73 & Pulmonary artery anomaly & $100(8)$ & $26(15)$ & 0.063 & .006 \\
\hline 746.02 & Stenosis of pulmonary valve, congenital & $30(3)$ & $15(8)$ & 0.060 & $<.001$ \\
\hline 747.21 & Anomalies of aortic arch & $9(1)$ & $10(6)$ & 0.049 & $<.001$ \\
\hline 745.6 & Endocardial cushion defect, unspecified type & $7(1)$ & $8(5)$ & 0.039 & $<.001$ \\
\hline 746.01 & Atresia of pulmonary valve, congenital & $69(6)$ & $17(10)$ & 0.038 & .048 \\
\hline 747.31 & Pulmonary artery coarctation and atresia & $77(6)$ & $18(10)$ & 0.037 & .066 \\
\hline 746.86 & Congenital heart block & $17(1)$ & $9(5)$ & 0.037 & .001 \\
\hline 746.83 & Infundibular pulmonic stenosis & $5(0)$ & $7(4)$ & 0.035 & .001 \\
\hline 745.12 & Corrected transposition of great vessels & $23(2)$ & $9(5)$ & 0.032 & .009 \\
\hline 745.19 & Other transposition of great vessels & $14(1)$ & $5(3)$ & 0.017 & .078 \\
\hline 746.3 & Congenital stenosis of aortic valve & $59(5)$ & $3(2)$ & -0.032 & .052 \\
\hline 746.1 & Tricuspid atresia and stenosis, congenital & $90(8)$ & $5(3)$ & -0.047 & .017 \\
\hline 747.1 & Coarctation of aorta & $139(12)$ & $12(7)$ & -0.048 & .056 \\
\hline 747.0 & Patent ductus arteriosus & $192(16)$ & $19(11)$ & -0.053 & .069 \\
\hline 746.85 & Coronary artery anomaly & $94(8)$ & $3(2)$ & -0.061 & .001 \\
\hline 745.5 & Ostium secundum type atrial septal defect & $235(20)$ & $19(11)$ & -0.089 & .005 \\
\hline 746.7 & Hypoplastic left heart syndrome & $535(45)$ & $35(20)$ & -0.248 & $<.001$ \\
\hline
\end{tabular}

Values are presented as $\mathrm{n}(\%)$. Ordered from greatest to least absolute risk difference. Positive absolute risk difference favors heterotaxy group, negative favors nonheterotaxy CHD. Only ICD codes with $P$ value $<.1$ are shown. ICD, International Classification of Diseases; $C H D$, congenital heart disease. *ICD-10 codes were translated to ICD-9 per Table E1. †ICD codes only available for 1199 of 1254 patients in the nonheterotaxy CHD group, 177 of 186 in the heterotaxy group. †Fisher exact test. 
TABLE E6. Univariate Cox model for survival estimates

\begin{tabular}{|c|c|c|c|c|}
\hline & \multicolumn{2}{|c|}{ Survival } & \multicolumn{2}{|c|}{ 6-mo conditional survival } \\
\hline & Univariate HR & $P$ value & Univariate HR & $P$ value \\
\hline Heterotaxy & 1.54 & .002 & 1.66 & .008 \\
\hline Age (y) & 1.00 & .723 & 1.02 & .051 \\
\hline Female & 1.03 & .787 & 0.93 & .596 \\
\hline \multicolumn{5}{|l|}{ Race } \\
\hline White & Ref & & Ref & \\
\hline African American & 1.73 & $<.001$ & 2.47 & $<.001$ \\
\hline Asian & 1.65 & .14 & 2.07 & .111 \\
\hline Hispanic & 1.13 & .426 & 1.45 & .07 \\
\hline Other & 1.40 & .294 & 2.22 & .042 \\
\hline Year of transplant & 0.96 & .01 & 0.97 & .241 \\
\hline \multicolumn{5}{|l|}{ Listing status } \\
\hline $1 \mathrm{~A}$ & Ref & & & \\
\hline 1B & 0.84 & .314 & 1.00 & .986 \\
\hline 2 & 0.94 & .785 & 1.02 & .949 \\
\hline \multicolumn{5}{|l|}{ Location } \\
\hline ICU & Ref & & Ref & \\
\hline Hospital non-ICU & 0.97 & .845 & 1.21 & .343 \\
\hline Home & 0.78 & .043 & 1.17 & .331 \\
\hline Inotrope support & 1.17 & .139 & 0.99 & .958 \\
\hline VAD support & 1.00 & .982 & 0.64 & .252 \\
\hline ECMO & 2.49 & $<.001$ & 0.69 & .277 \\
\hline Mechanical ventilation & 1.48 & .001 & 0.93 & .698 \\
\hline Positive DSXM & 1.24 & .118 & 1.10 & .613 \\
\hline Prior sternotomy/surgery for CHD & 1.11 & .494 & 1.07 & .736 \\
\hline Prior univentricular repair & 0.99 & .947 & 0.85 & .497 \\
\hline
\end{tabular}

$\overline{H R}$, Hazard ratio; Ref, reference category; $I C U$, intensive care unit; $V A D$, ventricular assist device; $E C M O$, extracorporeal membrane oxygenation; $D S X M$, donor-specific crossmatch; $C H D$, congenital heart disease.

TABLE E7. Multivariate stratified Cox model for survival estimates

\begin{tabular}{|c|c|c|c|c|c|}
\hline \multicolumn{3}{|c|}{ Survival } & \multicolumn{3}{|c|}{ 6-mo conditional survival } \\
\hline Covariate term & Adjusted hazard ratio & $\overline{\text { Adjusted } P \text { value }}$ & Covariate term & Adjusted hazard ratio & $\overline{\text { Adjusted } P \text { value }}$ \\
\hline Heterotaxy & 1.58 & .002 & Heterotaxy & 1.86 & .021 \\
\hline Year & 0.97 & .038 & Race: AA & NA* & \\
\hline Race: AA & NA* & & Age & NA* & \\
\hline ЕCMO & NA* & & & & \\
\hline
\end{tabular}

No significant interactions between terms in the final model were identified (data not shown). AA, African American; NA, not applicable; ECMO, extracorporeal membrane oxygenation. *Hazard ratio estimates not available because these terms were stratified in the Cox model because they violated the proportional hazards assumption (data not shown). 
TABLE E8. Univariate logistic regression comparisons for model building

\begin{tabular}{|c|c|c|c|c|c|c|c|c|}
\hline & \multicolumn{2}{|c|}{ Cardiac surgery } & \multicolumn{2}{|c|}{ Post-HT infection } & \multicolumn{2}{|c|}{ Post-HT dialysis } & \multicolumn{2}{|c|}{$\begin{array}{c}\text { Post-HT mechanical } \\
\text { ventilation }>1 \text { wk }\end{array}$} \\
\hline & $\begin{array}{c}\text { Univariat } \\
\text { OR }\end{array}$ & $P$ value & $\begin{array}{c}\text { Univariate } \\
\text { OR }\end{array}$ & $P$ value & $\begin{array}{c}\text { Univariate } \\
\text { OR }\end{array}$ & $P$ value & $\begin{array}{c}\text { Univariate } \\
\text { OR }\end{array}$ & $P$ value \\
\hline Heterotaxy & 2.12 & .002 & 1.50 & .028 & 2.16 & .002 & 1.42 & .032 \\
\hline Age & 0.99 & .51 & 0.97 & .003 & 1.02 & .007 & 0.93 & $<.001$ \\
\hline Female gender & 0.88 & .501 & 1.07 & .583 & 0.54 & .007 & 0.97 & .821 \\
\hline \multicolumn{9}{|l|}{ Race } \\
\hline White & Ref & & & & & & & \\
\hline AA & 1.69 & .039 & 1.09 & .636 & 0.84 & .581 & 0.98 & .895 \\
\hline Asian & 4.69 & .001 & 2.21 & .081 & 0.95 & .94 & 2.23 & .032 \\
\hline Hispanic & 1.28 & .365 & 0.84 & .368 & 1.12 & .672 & 0.89 & .453 \\
\hline Other & 0.32 & .27 & 1.16 & .704 & 0.76 & .706 & 0.89 & .752 \\
\hline Year & 1.01 & .635 & 0.96 & .012 & 1.01 & .836 & 0.98 & .105 \\
\hline \multicolumn{9}{|l|}{ Listing status } \\
\hline $1 \mathrm{~A}$ & Ref & & & & & & & \\
\hline 1B & 0.52 & .07 & 0.68 & .065 & 0.90 & .732 & 0.40 & $<.001$ \\
\hline 2 & 1.21 & .586 & 0.69 & .183 & 0.83 & .69 & 0.39 & $<.001$ \\
\hline \multicolumn{9}{|l|}{ Location } \\
\hline ICU & Ref & & & & & & & \\
\hline Hospital non-ICU & 0.85 & .557 & 0.56 & .002 & 0.27 & .001 & 0.62 & .007 \\
\hline Home & 0.70 & .112 & 0.44 & $<.001$ & 0.48 & .003 & 0.69 & .147 \\
\hline Inotrope support & 1.12 & .567 & 1.04 & .782 & 1.38 & .124 & 1.14 & .226 \\
\hline VAD & 2.23 & .009 & 1.34 & .248 & 1.96 & .039 & 1.33 & .182 \\
\hline ECMO & 2.22 & .005 & 2.61 & $<.001$ & 4.32 & $<.001$ & 7.51 & $<.001$ \\
\hline Pre-HT mechanical ventilation & 2.28 & $<.001$ & 2.46 & $<.001$ & 2.70 & $<.001$ & 5.18 & $<.001$ \\
\hline DSXM positive & 1.14 & .591 & 1.46 & .02 & 0.94 & .832 & $\mathrm{NA}^{*}$ & \\
\hline Prior sternotomy/CHD surgery & 1.09 & .712 & 1.28 & .11 & 1.15 & .579 & NA* & \\
\hline $\mathrm{H} / \mathrm{O}$ univentricular repair & 1.04 & .882 & 1.33 & .06 & 1.23 & .418 & NA* & \\
\hline Total Ischemic time $>3.5 \mathrm{~h}$ & $\mathrm{NA}^{*}$ & & & & 1.58 & .095 & $\mathrm{NA}^{*}$ & \\
\hline eGFR $<40$ & $\mathrm{NA}^{*}$ & & & & 3.19 & $<.001$ & $\mathrm{NA}^{*}$ & \\
\hline Pre-HT dialysis & NA* & & & & 13.95 & $<.001$ & NA* & \\
\hline
\end{tabular}

$H T$, Heart transplant; $O R$, odds ratio; Ref, reference category to which others are compared; $A A$, African American; $I C U$, intensive care unit; $V A D$, ventricular assist device; $E C M O$, extracorporeal membrane oxygenation; $D S X M$, donor-specific cross-match; $N A$, not applicable; $C H D$, congenital heart disease; $H / O$, history of; $e G F R$, estimated glomerular filtration rate. *Univariate comparison not performed. 
TABLE E9. Final multivariate logistic regression models

\begin{tabular}{|c|c|c|}
\hline Covariate term & $\begin{array}{c}\text { Adjusted } \\
\text { OR }\end{array}$ & $\begin{array}{c}\text { Adjusted } \\
P \text { value }\end{array}$ \\
\hline \multicolumn{3}{|l|}{ Cardiac surgery } \\
\hline Heterotaxy & 1.98 & .006 \\
\hline Race: White & 0.70 & .075 \\
\hline VAD & 1.92 & .038 \\
\hline Pre-HT mechanical ventilation & 2.24 & $<.001$ \\
\hline \multicolumn{3}{|l|}{ Post-HT infection } \\
\hline Heterotaxy & 1.55 & .023 \\
\hline Year of HT & 0.96 & .022 \\
\hline ECMO & 1.59 & .059 \\
\hline Pre-HT mechanical ventilation & 1.81 & .001 \\
\hline Location: home & 0.67 & .013 \\
\hline Positive DSXM & 1.40 & .044 \\
\hline Prior univentricular repair & 1.32 & .086 \\
\hline \multicolumn{3}{|l|}{ Post-HT dialysis } \\
\hline Heterotaxy & 2.58 & .001 \\
\hline Pre-HT dialysis & 8.62 & $<.001$ \\
\hline Female gender & 0.51 & .006 \\
\hline ECMO & 2.17 & 018 \\
\hline Location: ICU & 1.65 & .045 \\
\hline Total ischemic time $>3.5 \mathrm{~h}$ & 1.72 & .058 \\
\hline eGFR $<40$ & 2.55 & .003 \\
\hline \multicolumn{3}{|c|}{ Post-HT mechanical ventilation $>1$ wk } \\
\hline Heterotaxy & 1.70 & .003 \\
\hline ECMO & 4.11 & $<.001$ \\
\hline Pre-HT mechanical ventilation & 3.61 & $<.001$ \\
\hline Age (y) & 0.96 & $<.001$ \\
\hline
\end{tabular}

TABLE E10. Linear regression model of total ischemic time

\begin{tabular}{lrlr}
\hline \multicolumn{1}{c}{ Covariate } & Coefficient & \multicolumn{1}{c}{$\mathbf{9 5} \%$ CI } & $\boldsymbol{P}$ value \\
\hline Heterotaxy & 19.17 & $(10.89$ to 27.46$)$ & $<.001$ \\
Year of transplant & 1.16 & $(0.46$ to 1.86$)$ & .001 \\
Hispanic race & 8.13 & $(0.53$ to 15.73$)$ & .036 \\
Location: home & 13.42 & $(7.46$ to 19.38$)$ & $<.001$ \\
Distance between OPOs (miles) & 0.13 & $(0.12$ to 0.14$)$ & $<.001$ \\
Prior univentricular repair & 6.07 & $(-0.93$ to 13.07$)$ & .089 \\
Constant & -2165.27 & $(-3571.95$ to -758.60$)$ & .003 \\
\hline
\end{tabular}

CI, Confidence interval; $O P O$, Organ Procurement Organization. 
TABLE E11. Hospitalization cost and cost breakdown

\begin{tabular}{lrcrcc}
\hline & \multicolumn{1}{c}{ Nonheterotaxy CHD } & & Heterotaxy & \multicolumn{1}{c}{ value } \\
\hline Total cost after HT & 378,495 & $(261,770-576,221)$ & 449,011 & $(320,080-710,692)$ & .001 \\
Pharmacy costs & 30,008 & $(18,011-62,295)$ & 45,767 & $(23,588-87,732)$ & .000 \\
Lab costs & 26,136 & $(16,374-47,399)$ & 33,320 & $(18,273-71,766)$ & .004 \\
Imaging costs & 8148 & $(3739-15,625)$ & 10,855 & $(4358-19,884)$ & .001 \\
Supplies costs & 13,535 & $(7347-26,703)$ & 16,370 & $(8074-31,916)$ & .090 \\
Clinical costs & 187,931 & $(119,210-266,740)$ & 205,137 & $(139,825-283816)$ & .048 \\
Other costs & 82,245 & $(53,870-141,743)$ & 100,512 & $(62,045-201,019)$ & .002 \\
\hline
\end{tabular}

Costs are in adjusted to 2016 inflation, presented as median cost (interquartile range). Other costs constitutes predominately rooming and nursing charges. $C H D$, Congenital heart disease; $H T$, heart transplant.

TABLE E12. Hospitalization cost and cost breakdown, conditional on survival to discharge

\begin{tabular}{|c|c|c|c|c|c|}
\hline \multirow[b]{2}{*}{ Total cost after HT } & \multicolumn{2}{|c|}{ Nonheterotaxy CHD } & \multicolumn{2}{|c|}{ Heterotaxy } & \multirow{2}{*}{$\frac{P \text { value }}{.001}$} \\
\hline & 360,211 & $(251,672-527,349)$ & 421,040 & $(298,588-666,392)$ & \\
\hline Pharmacy costs & 27,877 & $(1754-54,045)$ & 43,025 & $(19,927-80,849)$ & .000 \\
\hline Lab costs & 23,740 & $(15,652-40,543)$ & 28,507 & $(17,178-55,377)$ & .010 \\
\hline Imaging costs & 7800 & $(3629-14,736)$ & 10,521 & $(4743-18,890)$ & .001 \\
\hline Supplies costs & 11,830 & $(6957-24,540)$ & 14,889 & $(7065-29,305)$ & .190 \\
\hline Clinical costs & 180,428 & $(116,189-257,664)$ & 197,117 & $(136,997-270,880)$ & .076 \\
\hline Other costs & 79,614 & $(53,041-134,655)$ & 100,962 & $(62,045-194,149)$ & .001 \\
\hline
\end{tabular}

Costs are adjusted to 2016 inflation, presented as median cost (interquartile range). Other costs constitutes predominately rooming and nursing charges. $C H D$, Congenital heart disease; $H T$, heart transplant. 